\title{
Haluk Perk Müzesi'nden Örnekler Eşliğinde Bizans İmparatorluğu Döneminde İnanç, Münzevi Yaşam, Hac ve Hacılık Kavramları
}

\author{
Faith, Asceticism and The Concepts of Pilgrim and Pilgrimage in The Byzantine Empire \\ with Samples from Haluk Perk Museum
}

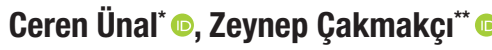

\section{Öz}

İstanbul'da bulunan Haluk Perk Müzesi, nadir örnekler barındıran zengin koleksiyonuyla ülkemizin özel müzeleri arasında saygın bir yer edinmiştir. Haluk Perk tarafından 1995 yılında müzeye dönüştürülen bu koleksiyon, Bizans Dönemi’ne ait çok farklı kategoride esere de ev sahipliği yapmaktadır. Makalemizde, bu koleksiyondan Bizans dünyasındaki inanç, münzevi yaşam, hac ve hacılık kavramların sanata nasıl yansıdığı hakkında bilgi veren, toplam on beş adet eser konu edilmektedir. Bizans İmparatorluğu'nun farklı dönemlerine tarihlenen bu eserler arasında bir hacı tokeni; taşınabilir nitelikte iki küçük ikona; kutsal kişi tasvirleriyle bezeli dokuz enkolpion ile takılara ait üç bronz obje yer almaktadır. Söz konusu eserler, üzerlerindeki zengin ikonografinin bir anlam kazanabilmesi ve ortaya çıkmalarında hâkim olan düşüncenin neler olduğunun daha iyi anlaşılabilmesi amacıyla, Bizans dünyasındaki inanç ve ibadet ilişkisine vurgu yapan birtakım kavram, kişi ve fikirlerle birlikte ele alınmıştır. İkonografileri, üslupları ve benzer örnekleri göz önüne alınarak incelenen ve tarihlendirilen bu eserler, Bizans Sanatı'nın Anadolu buluntusu nadir ve özgün örnekleri olmaları bakımından da son derece önemlidir.

\section{Anahtar Kelimeler}

Haluk Perk Müzesi, İnanç, Münzevi Yaşam, Hac, Enkolpion, Bizans

\begin{abstract}
Haluk Perk Museum in Istanbul has gained a prestigious place among the private museums of our country with its rich collection containing rare examples. The collection, which was turned into a museum by Haluk Perk in 1995, also includes many different categories of works from the Byzantine Period. In our article, a total of fifteen works from this collection, which give information about the beliefs, ascetic life, cross and pilgrimage concepts in the Byzantine world and how they are reflected in art, are discussed. Of these works, which are dated back to different periods of the Byzantine Empire, there is one pilgrim's token, two icons that are portable, nine encolpia decorated with the depictions of saints and three bronze objects of jewelry. The works in question were handled together with the concepts, people and ideas emphasizing the relationship between belief and worship in the Byzantine world in order for the rich iconography in them to gain a meaning and to be able to better comprehend what the dominant thought was in their emergence. The works, which have been examined and dated considering their iconography, styles and similar examples, are extremely important in terms of being rare and unique examples of Anatolian finds within the scope of Byzantine Art.
\end{abstract}

\section{Keywords}

Haluk Perk Museum, Faith, Asceticism, Pilgrimage, Encolpion, Byzantine

* Sorumlu Yazar: Ceren Ünal (Prof. Dr.) Manisa Celal Bayar Üniversitesi, Fen-Edebiyat Fakültesi, Sanat Tarihi Bölümü, Manisa, Türkiye. E-posta: cerenunalcbu@gmail.com ORCID: 0000-0002-1563-735X

** Zeynep Çakmakçı (Doç. Dr.) Dokuz Eylül Üniversitesi, Edebiyat Fakültesi, Müzecilik Bölümü, İzmir, Türkiye. E-posta: zeyneporals@yahoo.com ORCID: 0000-0002-8599-0204

Attf: Unal, Ceren ve Cakmakci, Zeynep. “Haluk Perk Müzesi’nden Örnekler Eşliğinde Bizans İmparatorluğu Döneminde İnanç, Münzevi Yaşam, Hac ve Hacılık Kavramları.” Art-Sanat, 14(2020): 495-531.

https://doi.org/10.26650/artsanat.2020.14.0019 


\section{Extended Summary}

In the process of the spread of Christianity, the development of the concepts of faith and worship began to appear through various pursuits. In the early Christian period, the believers chose to spend all their lives devoting themselves entirely to spiritual life and being free of worldly pleasures in order to be closer to God and to become true disciples. These people, who are described as hermit monks and ascetics, were revered as saints. The believers regarded them as a saints after their death. Some of them passed away redeeming themselves from sins and some became martyrs because of their faith. Both life processes have not lost their popularity since the $4^{\text {th }}$ century to the present day because they represent devoted lives for Christianity and serve as a model for other believers as well. There are various objects including depictions of Saint Symeon Stylites the Younger, Saint Onouphorios, Saint Nicholas, Saint Tryphonos, and Soldier Saints Georgios and Demetrios, who became the instructive and revered saints of the Christian world from different regions and with different life stories. The concept of carrying objects containing depictions of the saints, which are thought to be protective because the saints sacrificed their lives for a sacred purpose and believed to have healing abilities, and going on pilgrimage by visiting saints' tombs, which are believed to be sacred since they were buried there or martyred, have been accepted in Byzantine society since the $4^{\text {th }}$ century onwards.

Along with the spread of Christianity, it is visible that the concepts of pilgrim and pilgrimage gained importance. The facts of pilgrim and pilgrimage are identified with the spiritual journey to the loca sancta between the beginning of the $4^{\text {th }}$ century and the $7^{\text {th }}$ century. The believers following the traces of the spiritual journey on which Constantine I's mother Helena once had gone to find the true cross where Jesus had been crucified has hence developed into the concept of pilgrimage. The purpose of pilgrimage travel differs according to believers. The main reasons for pilgrimage are worship, donations and offerings, redemption of sins or getting advice to heal physical or mental ailments. The pilgrims purchased souvenirs made of various materials from the loca sancta or the sacred area visited on the route. As the popularity of pilgrimage increased, so did the variety of souvenirs or protective objects purchased by pilgrims. Encolpia, pilgrimage flasks, oil lamps, censers, tokens rings, liturgical seals and cross pendants were bought by pilgrims. The concept of pilgrim on the other hand is fully associated with the ascetic life in Early Christianity. Christian believers, who performed a pilgrimage by visiting a loca sancta, also showed great interest in ascetic monks who have a very important place in Early Christianity. Ascetic monks who established a life that isolated themselves from worldly riches for eternal salvation were later honored by being declared saints. For centuries, pilgrimage has been performed to pay homage to the hermit monks who have played an important role in the beginning of the Christian faith and are examples for conveying this doctrine to believers, and these sacred visits are maintained within the same emotion and faith today as well. 
Haluk Perk Museum, which has quite original and various objects dated back to different periods of the Byzantine Empire, has a distinguished position in Turkey. The token, medallion pendants and small icons in the Haluk Perk Museum stand out as important concrete documents that provide information about faith, worship and pilgrimage. As well as the depictions of pillar saints or martyr saints, these objects including depictions of Mary with the title of Mother of God and whose protective identity is emphasized contain both faith and protective and healing talisman functions. The terracotta token, the small hematite icon, the small steatite icon, three medallions and nine encolpia date back to the Early Byzantine Period. They will be presented in detail. They are also very important objects to emphasize the features of their periods. The pilgrim token, which occupies a privileged place among these objects, is a typical example of the Symeon token of the $6^{\text {th }}$ and $7^{\text {th }}$ centuries. This token, one of the rare specimens found in Turkey, is probably of Antioch origin. The double sided icon, which is made of hematite and contains Saint Onouphrios on the one side and the "Daniel in the lions' den" depiction from the Old Testament on the other side, must have been made for a devout Christian who believed that it would provide divine protection, goodness and healing. Although there is no clear information about the production date of the icon, it is thought that it can be dated between the $12^{\text {th }}$ and the $14^{\text {th }}$ centuries. The icons were proctective objects. The steatite is also believed to be a proctective substance. In our study, both of them will be discussed in a detailed way. The inscription on the object can be partly read because it is broken. However, since the person on the object has a bishop attire, he must be St Nicholas because it is his characteristic costume. Taking into consideration the popularity of steatite in the Byzantine world, the object has been ascribed to the period between the $11^{\text {th }}$ and the $13^{\text {th }}$ centuries. Three encolpia on which we see Virgin Mary in three different types of depiction are rare examples of which we cannot come across many similar ones. In the first one, the reverse was destroyed. In the second one, the reverse was devoted to the military Saint Georgios; in the third one, the martyr Saint Tryphonos of Nicaea is depicted. Although the encolpion varies according to the pendant, it is estimated that they belong to the period between the $10^{\text {th }}$ and $14^{\text {th }}$ centuries due to the depiction types and iconographic details of these three objects. The three bronze objects whose obverse and reverse have depictions and are probably attached to a similar medallion by means of rings are among the interesting examples of the collection. Although their exact forms are not certainly known, they are thought to be bracelets, necklaces, belts or pendant fragments. The objects having the inscriptions and depictions of saints were used in Christianity for centuries in order to obtain divine help. Finally, the six clover-shaped encolpion pendants included in the collection repeat one another in both the form and the depictions on them. It is known that this kind of pendant, which actually emphasizes a cross in its clover form, has become widespread since the $10^{\text {th }}$ century and it is under consideration that the examples in the museum date back to the $12^{\text {th }}$ and $14^{\text {th }}$ centuries. 


\section{Giriş}

İstanbul'da bulunan Haluk Perk Müzesi, nadir örnekler barındıran zengin koleksiyonu, bu koleksiyonun bilim dünyasına tanıtılması yönündeki gayretleri, bu amaçla düzenlediği veya katkıda bulunduğu sergiler, nitelikli akademik yayınlarıyla ülkemizin özel müzeleri arasında örnek ve saygın bir yer edinmiştir. Haluk Perk tarafından 1995 yılında müzeye dönüştürülen koleksiyon, farklı dönemlere ait eserler yanında, Bizans dönemine tarihlenen çok farklı kategoride esere de ev sahipliği yapmaktadır. Makalemizde bu koleksiyondan seçilmiş özellikle Bizans dünyasında inanç, münzevi yaşam, hac ve hacılık kavramlarının sanata nasıl yansıdığı hakkında önemli bilgiler sunan, toplam on beş adet eser konu edilmektedir. Makalemizde, söz konusu eserlerle ilgili detaylı bilgi ve değerlendirmeye yer verilmiştir. Ancak yaratılmalarındaki farklı etkilerin ve üzerlerinde yer alan zengin ikonografinin daha doğru anlaşılabilmesi için eserlerin tanıtımı öncesinde, Bizans dünyasında etkili olan bazı inanç ve ibadet şekilleri ile bunlarla bağlantılı kişi ve kavramlar hakkında kısa bilgi vermenin faydalı olacağı düşünülmüştür. Bu bağlamda, Haluk Perk Müzesi'nden seçilen eserlerle ilgili olarak inançlı Hristiyanlar için zorlu yaşantılarıyla örnek model oluşturan çilekeş azizler ve seçtikleri münzevi yaşam hakkında bilgi verilmiş ve "hac" ve "hacılık" kavramlarının Bizans toplumundaki anlamı üzerinde durulmuştur.

\section{Erken Hristiyanlık Döneminde Münzevi Yaşam ve Çilekeş Azizler}

Münzevi bir yaşamı tercih edip, dünyevi zevklerden ve toplu yaşam biçiminden kendilerini soyutlayarak göksel gücün ruhani desteğini alacaklarına inanan keşişler, Erken Bizans dönemi sanatında oldukça ilginç örneklerle karşımıza çıkar. Toplu yaşam biçimi ve manastır oluşumunun öncesinde bireysel tercihleri doğrultusunda Mısır'da çölde ya da ıssız bir yerdeki mağarada tek başına inzivaya çekilerek ibadetini gerçekleştiren keşişlerin daha sonra Aziz unvanı ile onurlandırılarak hürmet görmeleri sağlanmıştır. İmparator Decius zamanında (MS. 249-251) Romalıların baskı ve zulümlerinden kurtulmak amacıyla münzevi bir hayatı seçen ilk kişi, Havari Paulos'la karıştırılmaması için "İlk Münzevi” olarak da tanımlanan Paulos’tur. Mısır çöllerindeki bir mağarayı kendine mesken edinen Paulos, son derece kısıtlı imkânlarla sürdürdüğü yaşamıyla çilekeşliğin öncüsü olmuştur'. ${ }^{1}$ Mısır'da zengin bir köylü ailesinin oğlu olarak dünyaya gelen Aziz Antonios da, İsa'nın, "Git, neyin varsa sat, fakirlere ver ve ardımdan gel" sözünü benimseyip, 269 yılından itibaren münzevi bir hayatı seçen ilk kişilerden biridir. Çöllerde geçirdiği yetmiş yıl ona, zihnin beden üzerindeki ilahi hâkimiyetini kazandırmış ve Hristiyan dünyasınca kendisine hayranlık duyulmasını

1 Rivayete göre su ihtiyacını yaşadığı yerin yakınında bulunan bir pınardan karşılayan bu ilk münzevi, palmiyelerden de kendisine bir giysi yapmıştır. Anlatıldığına göre, ona her gün bir somun ekmek getiren bir karga tarafindan beslenen Paulos, ihtiyaçlarını bu şekilde karşılayarak 60 yıl boyunca huzurlu bir yaşam sürer. Bkz. Alice-Mary Talbot, "Bizans Manastır Sistemine Giriş," COGITO 17 (1999), 163. 
sağlamıştır². Diğer taraftan Aziz Antonios’un Paulos’tan farkı, tek başına değil müritleriyle birlikte yaşamasıdır. Bu tercihiyle Aziz Antonios aynı zamanda ilk manastır topluluğunun da temellerini atmış ve böylece inançlı Hristiyanlara nefsi körelterek kutsiyete erişmenin yeni bir yolunu göstermiştir³

4. yüzyılda Mısır Çölü’nde münzevi bir yaşamı tercih ederek kendisini Tanrıya ve Hristiyan inancına adayan önemli azizlerden biri de Aziz Onouphrios'tur ${ }^{4}$. Haluk Perk Müzesi'nde yer alan hematit bir ikonanın bir yüzünde de karşılaştığımız Aziz Onouphrios, Erken Hristiyanlık öğretisinin günümüze kadar popülerliğini yitirmemiş önemli temsilcilerindendir. Yoğun ve güçlü bir maneviyat içinde, dünyevi hayatın zevklerinden yoksunluk ve nefsini inkârla geçen bir yaşam sürdüren Aziz Onouphrios, Mısır çöllerinde geçirdiği yapayalnız atmış ya da yetmiş çileli yılla, inancın gücünü tüm insanlara göstermeyi başarır. Sert hava koşullarına, açlığa ve şeytanın türlü kandırmalarına dayanarak hayatta kalmayı başardığı yaşam hikâyesi, ömrünün sonlarına doğru çölde karşılaştığı başrahip Paphnutius tarafından kaleme alınmıştır5. Paphnutius, aslında çilekeş bir yaşam hakkında daha çok şey öğrenmek, yerel münzevilerle tanışmak ve kendisi de münzevi bir hayatı deneyimlemek için çölde uzun bir yolculuğa çıkmıştır. Bu yolculuk sırasında başrahip, azizi çölde, bedeni bir hayvan gibi kürkle kaplı (bazı anlatılara göre dört ayak üzerinde yürürken) ve bir deri bir kemik denebilecek kadar zayıflamış olarak bulmuştur. Palmiye yapraklarından yaptığı bir peştamal giyen aziz, aynı zamanda uzun saç ve sakalıyla dikkat çekmektedir. Gördüğü manzara karşısında ilkin aşırı derecede endişe ve korku duyan Paphnutius, akşamını bu kutsal adamla sohbet ederek ve Tanrı tarafından mucizevi bir şekilde verilen basit bir yemeği paylaşarak geçirmiştir ${ }^{6}$. Bu sohbet sırasında Aziz Onouphrios, Paphnutius'u yaklaşan ölümü hakkında uyarmış ve öldükten sonra onu gömmesi için talimatlar vermiştir? Ertesi sabah hayatını kaybeden aziz, ölmeden önce söylediği son cümlelerindeki isteği üzerine, başrahip tarafından bir kaya oyuğuna gömülmüştür ${ }^{8}$. Oyuk, aziz gömüldükten sonra hızlıca üzerine kapanmış ve aziz yaşadığı yerin yakınındaki bir hurma ağacıyla birlikte ortalıktan kaybolmuştur. Yaşadığı bu olay üzerine artık çölde kalamayacağını anlayan Paphnutius ise manastırına geri dönerek, azizle tesadüfen karşılaşmasının

2 Peter Brown, "Yeni Toplum: Manastır Sistemi ve Hıristiyanlığın Yayılışı 300-400," Geç Antik $\quad$ Ç a $\breve{g} d a$ Roma ve Bizans Dünyast (İstanbul: Tarih Vakfı Yayınları, 2000), 57.

3 Talbot, "Bizans Manastır Sistemine Giriş", 164.

4 Alexander Kazdhan ve Nancy Peterson Ševčenko, "Onouphrios," Oxford Dictionary of Byzantium (New York: Oxford University Press, 1991), 2:1527.

5 Aziz'in 4. yüzyılda başrahip Paphnutius tarafından Kıptice yazılan hikâyesinin İngilizce çevirisi ve ayrıntıları için bkz. Paphnutius, Histories of the Monks of Upper Egypt and The Life of Onnophrius, çev. Tim Vivian (NJ, USA: Gorgias Press, 2009), 143-166.

6 Leslie Ross, "Onuphrios," Holy People of the World, Cross-Cultural Encyclopedia, c. 2, ed. Phyllis G. Jestice (USA: ABC-CLIO, 2004), 657.

7 Leslie Ross, “Onuphrius, Saint,” Medieval Art: A Topical Dictionary (Westport CT: Greenwood Press, 1996), 189.

8 Paphnutius'un azizi bir kaya oyuğu yerine, iki aslanın yardımıyla kazdığı bir mezara gömdüğü de söylenmektedir. Bu bilgi için bkz. Ross, "Onuphrius, Saint," 189. 
hikâyesini yazmaya başlamıştır'. Başrahibin bu hikâyesi, Aziz Onouphrios'un sanattaki betimleri içinde bir kılavuz görevi görmüştür. Özellikle Ortaçağ Bizans tasvir sanatında aziz, uzun saç ve sakalı yanında zayıf hâli ve vahşi görünümüyle kolayca tanınabilir. Bazı Ortaçağ kumaş yapım loncalarının ve dokumacılarının Onouphrios'u keçeleşmiş saç ve sakalı ile palmiye yapraklarından dokunmuş kıyafeti nedeniyle koruyucu azizleri olarak kabul ettikleri de söylenmektedir. ${ }^{10}$

Kendini Tanrı'ya adayarak inzivaya çekilen Aziz Onouphrios gibi münzevilerin belki de en ilginci, bu çilekeş yaşamı mağara ve çöller yerine bir sütun üzerinde geçirmeyi tercih eden Stylitesler, yani sütun azizleridir. Bunların en ünlüsü ve öncüsü 4. yüzyılda bugün Suriye'nin Halep kenti yakınlarında bulunan Telanissos'ta bir sütun üzerinde yaşayan Aziz Yaşlı Symeon Stylites'tir ${ }^{11}$. Bu azizin çilekeş yaşamı, 6. yüzyılda ismi kadar yaşam biçimiyle de kendisine benzeyen Aziz Genç Symeon Stylites tarafından da örnek alınmıştır ${ }^{12}$. Günümüzde Antakya'nın Samandağ ilçesi sınırlarında kalan Mucizeler Dağı'nda çıktığı bir sütun üzerinde yaşadığı bilinen Genç Symeon Stylites' in verdiği vaazlar ve bulunduğu kehanetlerle ünlendiği ve zaman içinde Hristiyan dünyasında saygın bir yer edindiği anlaşılmaktadır. Genç ve Yaşlı Symeon'un bu aykırı yaşam tarzları ve haklarında anlatılan mucizeler, çileli hayatlarının bir efsaneye dönüşmesini sağladığı gibi sütun azizliği kavramının Bizans dünyasında yayılmasına da yardımcı olmuştur. Günümüzde her iki azizin de üzerinde yaşadıkları sütunun çevresine, biri Antakya, diğeri Suriye'de olmak üzere kiliseler inşa edilmiş ve sütun etrafında oluşturulan bu dini yapı grupları yüzyıllar boyunca inananlar tarafından hac merkezi olarak ziyaret edilmiștir. Bu ziyaretler sırasında hacıların hürmet göstermek için aldıkları hacı tokenleri (pilgrim token) ise aynı zamanda ruhani bir destek arayışının da ilk temsilcileridir. Çoğunlukla Yaşlı ve Genç Symeon Stylites tasvirleriyle dikkat çeken bu tokenler, karakteristik ikonografileriyle Erken Bizans döneminin en değerli sanat objeleri arasındadır.

9 Ross,"Onuphrios,” 657.

10 Ross, “Onuphrios," 657.

11 Hristiyanlıkta sütun azizleri ve bunları yaşam öykülerini anlatan çok sayıda çalışma bulunmaktadır. Bu konuda bkz. Frederick Lent, "The Life of St. Simeon Stylites: A Translation of the Syriac Text in Bedjan's Acta Martyrum et Sanctorum Vol IV," Journal of the American Oriental Society 35 (1915), 103-198; S. Ashbrook Harvey, "The Sense of a Stylite: Perspectives on Simeon the Elder," Vigiliae Christianae 42/4 (1988), 376-394; Robert Doran, The Lives of Simeon Stylites (Kalamazoo-Michigan: Cistercian Publications,1992); Antony Eastmond, "Body vs. Column: The Cults of St. Symeon Stylites," Desire And Denial in Byzantium, Papers from the Thirty-first Spring Symposium of Byzantine Studies, University of Sussex, Brighton, March 1997, ed. Liz James (Aldershot, UK: Ashgate Publishing, 1999), 87-100. Söz konusu azizlerle ilgili Türkçe yazılmıș birkaç çalıșma için bkz. İlkgül Kaya Zenbilci, "Münzevi Yaşam Fikrinin Bizans Tasvirlerindeki Yansımaları: Sütun Üzerinde Yaşayan Azizler," Sosyal Bilimlerde Güncel Akademik Çalıșmalar-2018, ed. M. Evsile, İ. Serbestoğlu ve T. Öcan (Ankara: Gece Kitaplığı, 2018), 3: 1-37; Murat Tural, Sütun Tepesinde Bir Ömür Aziz Simeon (İstanbul: Arkeoloji Sanat Yayınları, 2018).

12 Aziz Yaşlı ve Genç Symeon Stylites’in yașam hikâyeleri "Haluk Perk Müzesi Koleksiyonu’nda Yer Alan Bizans Dönemi Eserler" başlı̆̆ altında detaylı olarak ele alınmıştır. 


\section{Hristiyanlıkta Hac ve Hacılık Kavramı}

Yabancı ya da gezgin olarak farklı bir yeri ziyaret eden kişiyi tanımlayan hacı teriminin kökeni Latince peregrinus kelimesinden gelmektedir ${ }^{13}$. Özel bir anlam ifade eden bu yolculuk, kişiyi sadece inancı doğrultusunda oldukça uzak olabilecek bir mesafedeki kutsal mekâna götürmekle kalmaz, kutsal mekânda korunagelen rölik'e hürmetini göstermesini de sağlar. Kutsal kavramı, İsa'nın çarmıha gerildiği alan ya da gömüldüğ̈̈ yer olan mezarını ifade ettiği gibi, bir azize ait mezar alanı veya kutsal bir kişiye ait röliğin muhafaza edildiği mekân olarak da kullanılmıştır ${ }^{14}$. İnanan kişinin ister erkek, ister kadın olsun, gerçekleştireceği bu kutsal yolculuktaki en önemli amacı, kötülüklerden arınmak, huzur bulmak ve yaşamlarını inançlarına atfeden bu kutsal kişilere hürmet ve saygılarını gösterebilmektir. Kişi, bu uzun ruhani yolculuğa çıkmadan önce tüm dünyevi duygu ve isteklerinden arınmış olmalıdır ve hacı mertebesine ulaşmak için zorlu bir yolculuk geçirmek zorundadır.

Hristiyanlığın yayılması ile birlikte hac ${ }^{15}$ ve hacılık kavramlarının önem kazandığ görülmektedir. Hac ve hacılık olgusunun, 4. yüzyılın başları ile 7. yüzyıl arasında kutsal mekâna/loca sancta yapılan ruhani yolculuk ile özdeşleştiği anlaşılmaktadır ${ }^{16}$. I. Konstantinos'un annesi Helena'nın İsa'nın çarmıha gerildiği gerçek haçı bulmak için yaptığı ruhani yolculuğun izlerini takip eden inananlar böylece hac kavramını geliştirmişlerdir ${ }^{17}$. Hristiyanlığın erken dönemlerinden itibaren kutsal mekânlara yapılan

13 Pierre Maraval çalışmasında gerçekleştirilen bu seyahatin Latince "peregrinatio" kelimesi ile tanımlandığından bahsetmektedir. Pierre Maraval, "The Earliest Phase of Christian Pilgrimage in the Near East (before the 7th Century)," Dumbarton Oaks Paper 56 (2002), 63.

14 Jas Elsner, "Art and Pilgrimage," The Oxford Handbook of Byzantine Studies, ed. E. Jeffreys, J. Haldon ve R. Cormack, (Oxford: Oxford University Press, 2008), 742.

15 G. Vikan, Hoi polloi olarak tanımlanan hac yolcularının toplumun farklı sosyal tabakalarına ve meslek gruplarına mensup kişiler olduğundan bahsetmektedir. Bkz. Gary Vikan, Byzantine Pilgrimage Art (Washington D.C.: Harvard University Press, 1982), 3.

16 Gary Vikan, "Pilgrimage", Oxford Dictionary of Byzantium (New York: Oxford University Press, 1991), 3: 1676; V. Zalesskaya hacılık kavramının ve hac yolculuklarının iki farklı dönemde yoğun biçimde geliştiğinden bahsetmektedir. İlk dönem, 4.-7. yüzyıllar arasında, Erken Bizans Dönemi’nde gerçekleşmiştir. V. Zalesskaya, bu dönemde ana merkezinde Hristiyanlık olan ve Yunan yazıtları, Sasani etkisi, Suriye-Filistin ikonografisi ve Anadolu azizlerini barındıran farklı etkenler ve kültürel birikimlerin bir arada olduğunu anlatmaktadır. Bu dönemde hacılık kavramı hızla yayılmış ve oldukça uzak yerlerden kutsal mekânlara hac yolculukları yapılmıştır. Bu durum Bizans İmparatorluğu'nun doğusunun büyük bir bölümünün Araplar tarafından ele geçirilmesine kadar sürmüştür. Yazar ikinci önemli dönem olarak 10.-13. yüzyıllar arasını vermektedir. Bu iki döneme dair en önemli bilgiler yazılı kaynakların yanı sıra hacıların gittikleri yerden aldıkları hatıra ya da koruyucu içerikteki objelerin varlığıdır. Sadece bu dini içerikli ruhani yolculuğa çıkanların almasına odaklanarak üretilen bu eserler ise hac sanatı olarak da ifade edilebilen bir akımı ortaya çıkarmıştır. V. Zalesskaya, ilk dönem olan 4.-7. yüzyıllar arasında farklı etmenlerin bir arada olduğunu ama tamamen Hristiyan öğretisi ve geleneğine bağlı olan hacı sanatının ikinci dönemde güçlü bir İslami etki altına girdiği söylemektedir. Vera Zalesskaya, "Souvenirs of the Holy Land," Pilgrim Treasures from the Hermitage, Byzantium-Jerusalem (Amsterdam: Lund Humphries, 2005), 74.

17 Yuri Piatnitsky, “The Divine Light of the Faith and Power," Pilgrim Treasures from the Hermitage, Byzantium-Jerusalem (Amsterdam: Lund Humphries, 2005), 22; Zalesskaya, "Souvenirs of the Holy Land," 74; I. Konstantinos'un iktidarının hemen sonrasında Doğu Akdeniz, dindar yolcuların hac yolculukları ile oldukça canlanmıştır. Kutsal toprakların yoğun olarak Arap akınlarına maruz kaldığı 7. yüzyıldan itibaren de hac yolculuklarının kesintiye uğradığı bilinmektedir. Hac yolculukları ile ilgili dönemin tarihi ve teolojik kaynaklarında verilen bilgiler ise önemli belgelerdir. Bkz. Vikan, Byzantine Pilgrimage Art, 3. 
ziyaretler bilinmektedir. 4. ve 6. yüzyıllar arasında Beytüllahim, Nasıra ve Kudüs’te inşa edilen görkemli yapılar hacıların uğrak yerleri olmuştur ${ }^{18}$.

Kutsal topraklarda yaşanan bu görkemli dönem, 614 yılında Şah II. Hüsrev (590628) yönetimindeki Sasani istilası ile son bulmuştur ${ }^{19}$. Kudüs'ten alınan Gerçek Haç, 629 yılında Bizans imparatoru Herakleios'un (610-641) bölgenin kontrolünü ele geçirmesi sonucunda Kudüs'e tekrar geri getirilmiş ve kent bir daha Sasani hâkimiyetine girmemiştir. Fakat 637-640 yılları arasında Suriye-Filistin bölgesini Arapların ele geçirmiş, daha sonra Abbasi kontrolü altında giren bölge, 878 yılında Mısır'a dâhil olmuştur. Arapların bölgenin kontrolünü aldıkları erken dönemlerde halkın dini inançlarına müdahale etmedikleri ve Hristiyanların yaşamlarına devam ettikleri bilinmektedir. Bu tolerans içerisindeki dönemde hem Bizans, hem de Batı Avrupa'dan hacıların bölgedeki kutsal mekânları ziyaret etmek için geldikleri anlaşılmaktadır. Bu durum 9. yüzyılın başlarında değişmiş, Hristiyanlar din değiştirmeye zorlanmış, kutsal mekânları yıkılmaya başlanmış ve hacıların bölgeyi ziyaret etmelerine izin verilmemiştir. Bu sıkıntılı dönem Bizans İmparatorluğu ile Fâtımî Hanedanı arasında 1024 yılında yapılan anlaşma ile durulmuştur. Bizans imparatorunun himayesinde, bölgedeki kutsal mekânlar restore edilmiş ve hac yolculukları tekrar başlamıştır. ${ }^{20} 1078$ yılında Kudüs Selçukluların kontrolü altına girmiştir. Bu dönemden sonra bölgede hac faaliyetlerine dair iki farklı yorum bulunmaktadır. Kimi Hristiyan yazarlar, Selçuklu hâkimiyetinde bölgede hac faaliyetlerinin rahatça devam ettiğinden bahsederken kimi Bizans ve Latin kökenli kaynaklar ise Hristiyanların kötü muamele gördüğü ve hacıların taciz edildiği bilgisini vermektedir ${ }^{21}$. SuriyeFilistin bölgesi ve özellikle odak noktası olarak Kudüs, ilerleyen dönemde Haçlı Seferleri'nin başlıca amacı olmuş ve 11.-12. yüzyıllar arasında buranın kontrolü için savaşlar yapılmıştır. 1291-1517 yılları arasında Memlûkler ve 1517-1918 yılları arasında Osmanlı Devleti idaresi altındaki bölgelerde bulunan kutsal mekânlar, günümüzde de hâlâ hacıların uğrak yerleridir.

Kutsal topraklar dişında Suriye, Misır, Anadolu ve Yunanistan'daki kutsal kişilerin mezar yerleri ve kiliseleri de başlica ziyaret merkezleri hâline gelmiştir. Hac yolculuğunun amacı ise inananlara göre değişmektedir. Hac yolculuğunun en önemli nedenleri ise ibadet, bağış ve adak sunma, fiziksel ya da ruhsal rahatsılılıkları iyileştirmek

18 Piatnitsky, "The Divine Light of the Faith and Power," 22.

19 G. Ostrogorsky eserinde Kudüs’ün üç hafta süren kuşatma sonucunda İranlıların eline geçtiğinden bahsetmektedir. Bkz. Georg Ostrogorsky, Bizans Devleti Tarihi, çev. F. Işıltan (Ankara: Türk Tarih Kurumu Yayınları, 2015), 88; S. Mitchell ise eserinde Kudüs'ün ele geçirilmesi sonucunda İsa'nın gerildiği çarmıhın kalıntılarının II. Hüsrev'in hazinesine götürüldüğü bilgisini vermektedir. Bkz. Stephen Mitchell, Geç Roma Imparatorluğu Tarihi M.S. 284-641, çev. T. Kaçar (Ankara: Türk Tarih Kurumu Yayınları, 2016), 616, dipnot 884.

20 Piatnitsky, "The Divine Light of the Faith and Power," 22.

21 Piatnitsky, "The Divine Light of the Faith and Power," 23. 
için günahlarının kefaretini ödemek ya da öğüt almaktır ${ }^{22}$. Hac yolculuğunda ulaşılan kutsal mekândan ya da güzergâh üzerinde ziyaret edilen kutsal alandan hacılar tarafindan alınan objeler ise haç, kutsal su ya da yağ, bir tutam kum, polen, kurutulmuş çiçekler ve ikonalar gibi farklı form ve işlevlerde çeşitli malzemelerden üretilmiş eserlerdir. Erken Bizans döneminde hac yolculuğunun popülerliği arttıkça, hacılar tarafından alınan hatıra ya da koruyucu obje çeşitliliği de artmıştır. Aslında bunlar, günümüzde turizm amaçlı gezi sonunda alınan hediyelik eşyaların Erken Bizans dönemindeki dini içerikli ilk örnekleridir. Hacıların aldıkları objelerin arasına enkolpia, ampullae, kandiller, buhurdanlar (tütsü kapları), tokenler, yüzükler, litürjik mühürler ve haç kolye uçları da zamanla dâhil olmuştur ${ }^{23}$. Bu bakımdan hac yolculuğunun ruhani bir yolculuk olmasının yanı sıra ziyaret edilen bölge halkı için ticari bir getiri de sağladığı açıktır. Hacılar ise ziyaret ettikleri kutsal mekândan aldıkları bu hatıra eşyaları evlerindeki ibadet mekânlarında muhafaza ederek ya da üzerlerinde taşıyarak ruhani desteğin hep yanlarında olduğunu hissetmek istemişlerdir ${ }^{24}$. Bu objeler, kişiyi kötülüklerden ve şeytani güçlerden korudukları, iyileştirici ve şifa verici güce sahip oldukları düşünülerek alınmıştır.

Hacılık Erken Hristiyanlıktaki münzevi yaşam ile de özdeşleşmektedir. Kutsal bir mekânı ziyaret ederek hac görevini yerine getiren Hristiyan inananlar, Erken Hristiyanlıkta çok önemli bir yere sahip münzevi keşişlere de yoğun ilgi göstermişlerdir. Ebedi kurtuluş için kendilerini dünyevi zenginliklerden soyutlayan bir yaşam kuran münzevi keşişler daha sonra aziz ilan edilerek onurlandırılmışıtır. Hristiyan inancının başlangıcında önemli rol üstlenen ve bu öğretinin yayılması için inananlara örnek olan ve yol gösteren münzevi keşişlere hürmet göstermek için yüzyıllar boyunca hac yolculuğu gerçekleştirilmiştir ve bu kutsal ziyaretler günümüzde de aynı duygu ve inançla sürdürülmektedir ${ }^{25}$.

\section{Haluk Perk Müzesi Koleksiyonu'nda Yer Alan Bizans Dönemi Eserler}

Erken Hristiyanlık döneminde Tanrı'ya yakın, iyi bir inanan olmak için Suriye ve Anadolu'da oldukça ilginç formlarda münzevi yaşam tiplerinin ortaya çıtığı görülmektedir. Toplum yaşamından kendilerini soyutlayarak 1ssız yerlere çekilen münzeviler, genellikle bir mağara ya da ağaç içerisinde yaşamlarını sürdürme yolunu seçmişlerdir. Hatta dünyevi yaşamdan tamamen ayrılmak için bir sütun üzerinde tüm yaşamını geçiren Yaşlı Aziz Symeon Stylites bu bağlamda en iyi tanınan münzeviler-

22 Vikan, "Pilgrimage," 1676; Zalesskaya, "Souvenirs of the Holy Land," 74.

23 Zalesskaya, "Souvenirs of the Holy Land," 74; Elsner, "Art and Pilgrimage," 746; Y. Piatnitsky günümüzde, hacıların hatıra olarak aldıkları bu objelerin Avrupa, Kafkaslar, Kırım, Anadolu, Rusya, Mısır ve Ortadoğu olmak üzere çok geniş bir alanda bulundukları bilgisini vermektedir. Bkz. Piatnitsky "The Divine Light of the Faith and Power," 44.

24 Piatnitsky, "The Divine Light of the Faith and Power," 47.

25 Hacılık kavramı içerik olarak ilk inananların çektikleri çileleri hissetmek ve anlamak için yapılan kutsal bir yolculuğu ifade etmektedir. 
dendir ${ }^{26}$. Bir sütun üzerinde yaşamını geçiren münzeviler sütun azizi (stylites) olarak tanımlanmaktadır. Bu unvanı, Yunanca "stylos" yani sütun kelimesinden aldıkları bilinmektedir ${ }^{27}$. Yazılı kaynaklardan edinilen bilgiler doğrultusunda yetmiş kadar sütun azizinin varlığından söz edilmektedir ${ }^{28}$.

Çağdaşları ise sütun azizlerinin Tanrı tarafından geleceği görme ve şifacı yetilerle donatıldıklarına inanmışlardır. Bedenen ve ruhen tedavi edilmeye ihtiyacı olan kişiler, yardım almak için sütun azizinin bulunduğu yere gitmeye başlamış, münzevi yaşam tercihleri bu anlamda bozulan sütun azizi de zamanla çok bilinen bir kült hâline dönüşmüştür ${ }^{29}$.

$\mathrm{Bu}$ sütun azizlerinden en iyi bilineni Yaşl1 Symeon Stylites ${ }^{30}$ ve öğrencisi Genç Symeon Stylites'tir ${ }^{31}$. 4. yüzyılın sonlarında Nikopolis yakınındaki Sisa'da doğan Yaş1 Symeon yaşamının son otuz yedi yılını yaklaşık 16-18 metre yüksekliğindeki sütun üzerinde geçirdikten sonra 459 y1lında ölmüştür ${ }^{32}$. Öldükten sonra ise bugünkü Suriye topraklarındaki Halep kentinin kuzey batısındaki Qalat-Seman'da inşa edilen sekizgen planlı martyrium kilisede korunan röliği ile hürmet görmüştür ${ }^{33}$. Qalat Seman'daki Yaşlı Symeon Stylites'in martyrium'u Suriye'nin en görkemli hac mekânıdır. Mart-

26 Philippe Verdier, sütun üzerinde yaşamını tamamlayan çilecinin kollarını İsa'nın çarmıha gerilişi ve acısını hissetmek için iki yana açmaktan; ayakları ile bacaklarını hareket ettirmeden uzun süre aynı pozisyonda durmaktan dolayı bir süre sonra vücudunda yaralar açıldığından ve irinle kaplı bu yaraların kurtlandığından bahsetmektedir. Gönüllü olarak sürekli oruç hâlinde ve uykusuz kalan sütun azizi, bu sağlıksız yaşam koşullarını ölümüne kadar devam ettirmiştir. Philippe Verdier, “A Medallion of Saint Symeon the Younger,” The Bulletin of the Cleveland Museum of Art 67/1 (1980), 17. Yaralarından çıkan kurtların ise münzevinin kendi etiyle kutsandığ 1 düşüncesi hâkimdir. Bir terracotta ampulla üzerinde yer alan tasvirde de sütun azizinin yaralarından dökülen çok sayıda kurtçuk tasvir edilmiștir. Bkz. Verdier, "A Medallion of Saint Symeon the Younger," 25, dipnot 3 .

27 Verdier, "A Medallion of Saint Symeon the Younger," 25, dipnot 4.

28 Janette Witt, "Die Syrischen Säulenheiligen," Die Welt von Byzanz-Europas Östliches Erbe (München: Theiss 2004), 207

29 Verdier, "A Medallion of Saint Symeon the Younger," 17.

30 İyi eğitim almış Cyrrhus piskoposu kuzey Suriyeli Theodoretus'un (393-466) verdiği oldukça kısa bilgi, tarihçi Evagrius'un azizin yaşamına dair kısa notlarının yanı sıra Simeon'un müritlerinden Antony'in yazdığı biyografisi Yaşlı Stylites Symeon'un yaşamı hakkında bilgi edinilmesini sağlamaktadır. Bkz. Lent, "The Life Of St. Simeon Stylites: A Translation of the Syriac Text in Bedjan's Acta Martyrum et Sanctorum Vol. IV," 103; Alice-Mary Talbot, "Hagiography,” The Oxford Handbook of Byzantine Studies, ed. E. Jeffreys, J. Haldon ve R. Cormack (Oxford: Oxford University Press, 2008), 864.

31 Vikan, Byzantine Pilgrimage Art, 30-34.

32 Lent "The Life of St. Simeon Stylites: A Translation of the Syriac Text in Bedjan's Acta Martyrum et Sanctorum, Vol. IV," 103; Verdier, azizin yaşamının büyük bir kısmını dört farklı yükseklikteki sütun üzerinde geçirdiğini ve en yüksek olan son sütun üzerinde de yașamını yitirdiğini belirtmektedir. Bkz. Verdier, "A Medallion of Saint Symeon the Younger," 17. Yazar bunun yanı sıra azizin sütun üzerinde altmış yıldan fazla yaşadığını söylemekte ve bu rekorun ilk kez, altmış yıl bir sütun üzerinde yaşamış 6. yüzyıl stylites azizi Alypios; ikinci olarak da yaklaşık yüzyıl sütun üzerinde yaşamış 10. yüzyıl stylites azizi Lukas tarafindan kırıldığını ifade etmektedir. Bkz. Verdier, "A Medallion of Saint Symeon the Younger," 26, dipnot 12. Yaşlı Symeon'nun diğer bir müridi ve öğrencisi olan Stylites Daniel ise otuz üç yılını üç sütun üzerinde geçirerek seksen dört yaşında ölmüştür. Bkz. Verdier, “A Medallion of Saint Symeon the Younger,” 26, dipnot 12.

33 Bedeni ilk olarak Antakya'daki katedrale gömülmüş, daha sonra ise imparator I. Leon (457-474) tarafindan Konstantinopolis'teki martyrium'a taşınmıştır. Bkz. Verdier, “A Medallion of Saint Symeon the Younger,' 26, dipnot 8 . 
yrium 548 yılında yanmış ve Araplar tarafından harabe hâline getirilmesine rağmen azizin üzerinde yaşamını geçirdiği sütun günümüze kadar ayakta kalabilmiştir ${ }^{34}$.

Genç Symeon Stylites'in ise 521 yılında Antakya'da doğduğu ve yedi yaşındayken Seleucia Pieria' da $^{35}$ bir sütun tabanı üzerinde durduğu bilinmektedir. Azizin on iki yaşındayken 10 metre yüksekliğinde bir sütun üzerine taşındığı ve sonrasında da diyakoz olarak kutsandığ da ifade edilmektedir ${ }^{36}$. Tek başına kalabileceği bir yerde yaşamayı tercih eden aziz, Antakya'dan $10 \mathrm{~km}$ uzaklıktaki görkemli ve sarp bir coğrafyaya sahip Samandağ'a geçmiştir. Burada Klibanion olarak tanımlanan bir kaya üzerine sığınmış, yaşadığı yerin çevresinde müritleri küçük kulübeler yapmaya başlayınca, annesi Martha'nın tavsiyesi üzerine Qalat Seman'daki manastır kompleksini model alarak inşa işine girişmiştir. Kutsal Üçlü'ye atfen inşa edilen ana kilise sekizgen planlıdır ve daha sonra eklenen tüm yapıların merkezinde yer almaktadır. Yapının kuzey-güney yönüne kiliseler eklenmiştir. Sekizgen planlı yapının batısında ise atrium, propylaea ve keşişlerle hacıların kaldığı mekânlar bulunmaktadır. Tüm bu yapı kompleksi de Aziz Symeon'a görünen bir melek tarafından izleri belirlenen "mandra" yani kutsal duvarlarla çevrilmiştir. Sekizgen planlı yapı kompleksinin tam ortasına yerleştirilen sütun üzerine Aziz Symeon 4 Haziran 551 yılında tırmanmıştır. Sekizgen planlı yapının üzerinde üst örtü sistemi/bir çatı olmadığı için aziz, duvarlar içerisinde bulunan tüm alandaki her hareketi buradan gözlemleyebilir konumdadır ${ }^{37}$. Verdier'e göre Genç Symeon Hristiyan mistisizminin ileri düzeyde bir örneği olmasına rağmen, kendini tamamen dünyadan soyutlamış, içe kapanık ve asosyal bir karakter taşımaz; o, zamanla kendi topluluğuna hem iyi bir lider olmuş, hem de topluluğu dişındaki insanlara da iyi tavsiyelerde bulunan sevilen bir kişi hâline gelmiştir. Vaazlar vermiş, ilahiler bestelemiş ve birçok mektup yazmıştır. Sütunu üzerinde yaşadığı sırada, 554 yılında, rahip olarak kutsanmış ve 592 yılında da burada ölmüştür ${ }^{38}$.

Günümüze kadar ulaşmış her iki sütun azizi hakkındaki çağdaş literatür bilgilerinin yanı sıra, hem yaşadıkları yerdeki mimari kalıntılar, hem de madalyon, pandantif, yüzük, amulet ve diğer hediyelik eşyalardaki betimleri azizlerin ikonografisini ayrıntıyla sunan başlıca kaynaklardır. İyileştirici erdemler ile dolu olduğuna inanılan

34 Verdier, "A Medallion of Saint Symeon the Younger," 26, dipnot 9; Ayrıca, F. Lent, Symeon'dan çok daha uzun zaman önce bu bölgede Tanrıça Attarathe için yapılmış bir tapınak bulunduğunu ve yılda iki defa olmak üzere bir erkeğin uzun bir sütun üzerinde durarak tanrılar ile bağ kurmak için komünyon yaptığını anlatmaktadır. Bununla birlikte yazar, Yaşlı Stylites Symeon'un artık unutulmuş bu ayin hakkında herhangi bilgisi olmadığını da belirtmektedir. Bkz. Lent, "The Life of St. Simeon Stylites: A Translation of the Syriac Text in Bedjan's Acta Martyrum et Sanctorum, Vol. IV," 103.

35 Antakya'nın 35 km batısında, Musa Dağı'nın güneyinde, yaklaşık M.Ö. 300 yıllarında Büyük İskender'in komutanlarından Seleucus Nicator tarafından kurulmuş antik bir şehirdir. Günümüzde Hatay'ın Samandağı ilçesi sınırları içinde yer alır.

36 Verdier, "A Medallion of Saint Symeon the Younger," 19.

37 Verdier, "A Medallion of Saint Symeon the Younger," 19.

38 Verdier, "A Medallion of Saint Symeon the Younger," 19. 
reçine karıştırılmış topraktan, camdan, pişmiş topraktan ve kurşundan yapılmış çeşitli objeler ise yaşadıkları mekânı ziyaret eden hacılar için iyileştirici ve koruyucu bir işlev görmüştür ${ }^{39}$.

Bu tip objelerde Aziz Symeon Stylites'in tasvirinin yanında bir merdiven üzerinde yer alan melek tasvirine sıkça rastlanır ${ }^{40}$. Her iki stylit azizin yaşam öykülerini anlatan eserde de bu merdivenden hiç bahsedilmemekle birlikte, Genç Symeon Stylites ile ilişkili daha sonra yazılmış metinlerde merdivenler yer almıştır. Sütun ile sekizgen planlı yapı kompleksi arasında bir geçit işlevi gördüğü anlaşılan bu merdiven sayesinde ricalarını doğrudan azize iletebilen hacılar, aynı zamanda mum, tütsü, içi yağ dolu küçük şişeleri kutsaması için onun yanına kadar ulaşabilmektedir. ${ }^{41}$. İsa'nın çarmıhtan indirilmesi sırasında merdivenin kullanılmış olması stylit azizlere de benzer bir kutsallık atfedilmesi ile ilişkilendirilebilir.

Azizin başının üzerinde yer alan haç motifi ise Erken Hristiyanlık döneminde betimlenen kişinin kutsal statüsünün vurgulanması için sıklıkla tercih edilen bir uygulamadır. Yaşlı ya da Genç Symeon Stylites kültüyle ilişkili olarak sütun azizlerinin yaşadığı yeri ziyaret ederek hacı olan inananların buradan aldıkları kil tokenlerde de (eulogia) betimlenen stylit azizin başında bir haç motifi bulunmaktadır ${ }^{42}$.

\section{Pişmiş Toprak Hacı Nişanı/Hacı Tokeni (6.-7. yüzyıl)}

Envanter No: HPM 15574

Çap: $2,4 \mathrm{~cm}$,

Kalınlık:1 $\mathrm{cm}$

Ref: Bollmann 2008, 176-178, kat.no. 131. (6.-7. yüzyll); Vikan 1982, 34, fig. 25; 38, fig. 29a-b

39 Verdier, “A Medallion of Saint Symeon the Younger,” 19.

40 Elizabeth Key Fowden, "Der Heiligenkult im spätantiken Syrien,” Die Kunst Der Frühen Christen In Syrien, Zeichen, Bilder und Symbole, Vom. 4, Bis 7, ed. M. Fansa ve B. Bollmann (Oldenburg: Mainz am Rhein, 2008), 60; Beate Bollmann, "Katalog-Die Entwicklung Der Christlich-Byzantinischen Kultur Syriens," Die Kunst Der Frühen Christen In Syrien, Zeichen, Bilder und Symbole, Vom. 4, Bis 7, ed. M. Fansa ve B. Bolmann (Oldenburg: Mainz am Rhein 2008), 177-178, kat.no.131-132.

41 Verdier, "A Medallion of Saint Symeon the Younger," 19.

42 David Woods, “Some Dubious Stylites on Early Byzantine Glassware,” Journal of Glass Studies 46 (2004), 41. 

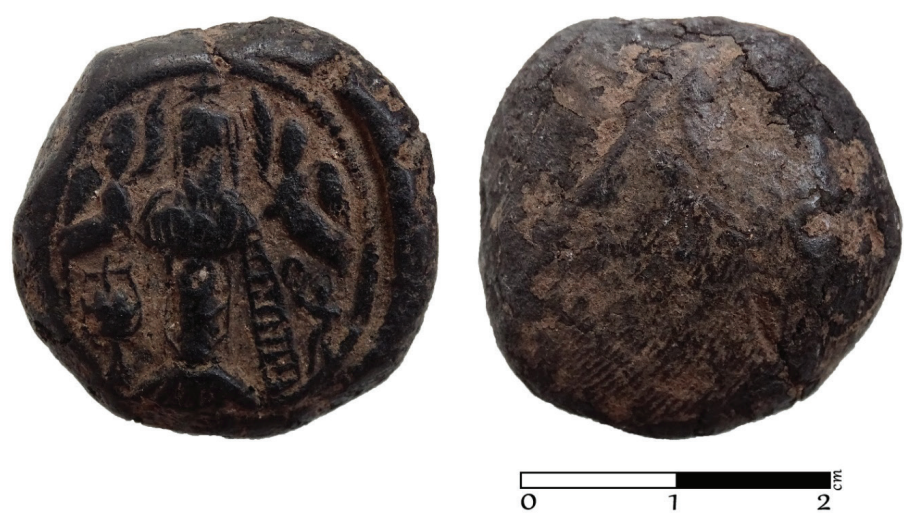

G. 1. Pişmiş Toprak Token (6.-7. yüzyı1) Ön ve arka yüz (Müze env no. HPM 15574) (Merve Toy, 2019)

Koyu kahverengi kil token/amulet üzerinde benzer örneklerden alışkın olduğumuz üzere sütun üzerinde belden yukarısı verilmiş ve stilize bir hâlde bir sütun azizi gösterilir (G.1, G.2). Azizin büstünün her iki yanında kanatları açık ve uçar vaziyette azize doğru yönelmiş meleklere yer verilmiş; sol tarafında ise bir merdiven tasvir edilmiştir. Azizin sütununun sol tarafında ve merdivenin hemen yakınında azize doğru eğilerek ona hürmet gösteren bir mürit ya da inanan resmedilmiş ve sağ tarafinda ise bir kantharos $^{43}$ betimlenmiştir $^{44}$. Eserin üzerinde tasvirin kimliğini tanıtacak herhangi bir yazıt yer almamaktadır. Müze ve özel koleksiyonlarda bulunan pişmiş topraktan yapılmış benzer hacı tokenlerine bakıldığında da resmedilen azizin kimliği çoğu zaman kesin olarak ifade edilemez. Bu nedenle tasvirdeki figür genellikle, Genç veya Yaşlı Symeon Stylites olmak üzere Bizans dünyasındaki iki ünlü stylitesin her ikisine birden atfedilir. $\mathrm{Bu}$ tip tokenlerde azizlerin kimliğini saptayacak ayrıcı ipuçlarının olmaması ve aşağı yukarı hepsinin kompozisyon düzenlemesi ve ikonografi açısından birbirine çok benzemesi dolayısıyla kesin bir ayrım yapmak kolay değildir. Bunları güvenli bir şekilde tarihlendirmek ve resmedilen azizin kimliğini açıkça belirleyebilmek, ancak objenin bir kazı buluntusu olması veya yapılacak materyal analizi ile mümkün olabilmektedir ${ }^{45}$. Bununla birlikte G. Vikan yaygın olarak "Symeon tokenleri" olarak adlandırılan bu hacı tokenlerinin Genç Symeon Stylites'le ilişkili olduğunu belirtmekte ve bunların azizin

43 B. Pitarakis, azizin yanında, onun yaşadığı sütunun çevresinden toplanan tozlardan oluşan ve şifa içerdiğine inanılan hnana olarak tanımlanan bir macunun muhafaza edildiği düşünülen bir kantharos ya da amfora olduğu bilgisini vermektedir. Ayrıca Pitarakis bu kil tabletlerin çeşitli hastalıkları iyileştirdiğine inanıldığını, kırılarak toz haline getirildiğini ve suyla içildiğini de ifade etmektedir. Bkz. Brigitte Pitarakis, "Şifayı Güçlendirmek Maddeler, Duyular ve Ritüeller," Hayat Kısa, Sanat Uzun Bizans ta Şifa Sanatı (İstanbul: Pera Müzesi Yayınları, 2015), 174.

44 Janette Witt, "Sechs Erdmedallions," Die Welt von Byzanz-Europas Östliches Erbe (München: Theiss, 2004), 209, 298-303; Janette Witt, "Styliten-Medallions," Rom und Byzanz Archäologische Kostbarkeiten aus Bayern (München: Hirmer Verlag, 1998), 106-107, 108 a-b.

45 Bollmann, "Katalog-Die Entwicklung Der Christlich-Byzantinischen Kultur Syriens,” 178. 
yaşadığı Mucizeler Dağı'ndan alınan kil ile yapıldıklarını ifade etmektedir ${ }^{46}$. Haluk Perk Müzesi'nde bulunan token de yazıta sahip olmamakla birlikte, bilinen örneklere yakın benzerliği dolayısıyla Symeon tokenlerinden biri olarak görülmektedir.

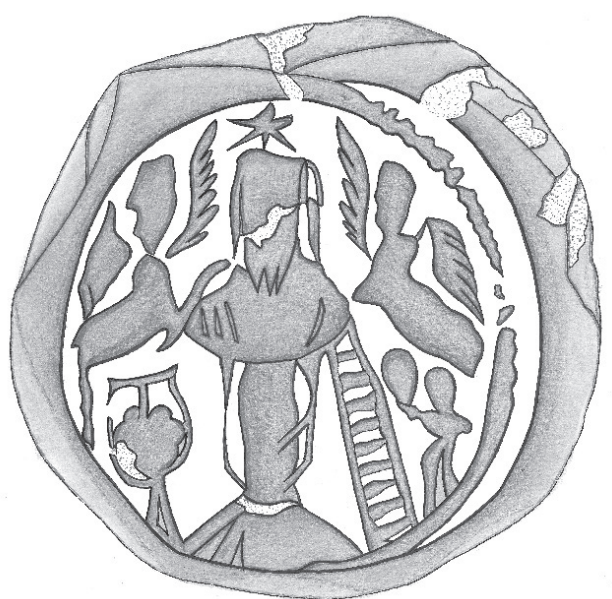

G. 2. Hacı Tokeni'nin ön yüz çizimi (Çizim: Z. Çakmakçı)

$\mathrm{Bu}$ tip tokenler, aziz tarafından kutsandığına inanılan bir tozdan yapılmış bir tür eulogiadır ve başlıca işlevi hastalıkları iyileştirmek ya da şifa vermektir ${ }^{47}$. Kil tokenin kenarlarındaki form bozukluğu ise iyileşmek için bir parça koparılıp sıvı ile karıştırarak içildiğini göstermektedir ${ }^{48}$. Haluk Perk Müzesi'ndeki hacı tokenin literatürde yer alan benzerleri dolayısıyla 6.-7. yüzyıla ait olduğu ve olasılıkla Antakya'da üretildiği düşünülmektedir. Bununla birlikte bu tokene hem form hem de ikonografik düzenleme açısından en yakın örnek, Suriye, Şam Ulusal Müzesi koleksiyonunda tespit edilmiştir ${ }^{49}$.

\section{Hematit Taşından Küçük İ́kona (12.-14. yüzyıllar)}

Envanter No: HPM 15573

Yükseklik: $4 \mathrm{~cm}$,

Genişlik:2.2 cm,

Kalınlık: $0.55-0.65 \mathrm{~cm}$

46 Gary Vikan, "Pilgrim Tokens,” Oxford Dictionary of Byzantium (New York: Oxford University Press, 1991), 3: 1678

47 Vikan, "Pilgrim Tokens," 1678.

48 Chris Entwistle, "Pilgrim Token with a Stylite," Byzantium-Treasures of Byzantine Art and Culture, ed. D. Buckton, (London: British Museum Press, 1994), 114, no.129; Chris Entwistle, "Pilgeramulett," Byzanz Pracht und Alltag (Bonn: Hirmer Verlag, 2010), 221, no.157; Janette Witt, "Sech Erdmedallions mit Stylitendarstellungen," Byzanz Das Licht aus dem Osten (Mainz: Verlag Phillip von Zabern, 2001), 183-184, I.67. Daha geç örnek için bkz. Antonis Tsakalos, "Lead Pilgrim Token of St Symeon," Everday Life in Byzantium, ed. D. Papanikola-Bakirtzi (Athens: Hellenic Ministry of Culture, 2002), 177, no. 200.

49 Kökeni Suriye olan ve Aziz Symeon Stylites Manastırı'na atfedilen M.S. 5-6. yüzyıla tarihli bu çok benzer token için bkz. http://www.unesco.org/culture/museum-for-dialogue/item/en/120/amulet-for-pilgrims, erişim 16 Aralık 2019. 
Ön yüz: Ön yüzde ayakta ve cepheden tasvir edilmiş Aziz Onouphrios tasviri yer almaktadır. Çıplak vücudunun sadece mahrem bölgesi palmiye yaprağ 1 ile kapatılan aziz, göğsünün ortasına kadar uzanan uzun sakalı ile orans pozisyonunda betimlenmiştir. Azizin her iki yanında sütun sıralı formda kimliğini tanıtan Yunanca bir yazıt bulunmaktadır (G.3, G.4).

Arka yüz: Bu yüzde ayakta ve cepheden Pers kostümü içerisinde Daniel (Danyal) Peygamber betimlenmiş ve ayaklarının iki yanında verilen stilize aslan tasvirleriyle de Eski Ahit’te yer alan "Daniel Aslanlar İninde" konulu hikâyeye gönderme yapılmıştır ${ }^{50}$. Peygamber dizleri üzerinde bulunan kısa tuniği ve boynunda düğümlediği kısa peleriniyle orans pozisyonunda resmedilmiştir. Başının iki yanına sütun sıralı hâlde Yunanca olarak adı yazılmıştır. Eser alt kısma doğru kırılmış ancak sonradan iki tarafına da delikler açılarak telle birbirine bağlanmıştır.

\section{Tablo 1}

Hematit Taşı İkona’nın Ön ve Arka Yüz Yazıtı ve transkripsiyonu (Haz. C. Ünal- Z. ÇakmakçıM. Bakouri) $)^{51}$

\begin{tabular}{|c|c|c|c|}
\hline \multicolumn{2}{|c|}{$\ddot{O n}$ yӥz } & \multicolumn{2}{|c|}{ Arka yüz } \\
\hline Sol & Sağ & Sol & Sağ \\
\hline АГІ & $\mathrm{H} \Theta(\mathrm{O} ?)$ & $\Phi$ & A $\Delta$ \\
\hline $\mathrm{OC}$ & $\Phi \mathrm{P}$ & ПР & $\mathrm{NH}$ \\
\hline & $\mathrm{HO}$ & & $\Lambda \mathrm{H}$ \\
\hline & $\mathrm{C}$ & & \\
\hline $\begin{array}{l}\mathrm{A} \Gamma \mathrm{IO} \Sigma \\
\text { (Hagios/Aziz) }\end{array}$ & $\begin{array}{l}\text { ONOYФPIO } \\
\text { (Onouphrios) }\end{array}$ & $\begin{array}{l}\text { ПРОФНТН } \Sigma \text { (Prophitis/ } \\
\text { Peygamber) }\end{array}$ & $\begin{array}{l}(\triangle \mathrm{ANH} \Lambda \mathrm{H}, \text { doğru yazılış1; } \\
\Delta \mathrm{ANIH} / \text { Daniel/Danyal })\end{array}$ \\
\hline
\end{tabular}

Bir yüzünde 4. yüzyılda yaşadığına dair bilgiler bulunan Aziz Onouphrios tasviri, diğer yüzünde Eski Ahit’te anlatımı bulunan "Daniel aslanlar ininde" betiminin yer aldığı bu küçük ikona, bu azizlerin kutsal koruyuculuğuna inanan dindar bir Hristiyan'ın kişisel kullanımı için yapılmış olmalıdır.

50 Majeska, Daniel Peygamber'in Doğu'da ve Batı'da iki farklı üslup içerisinde betimlendiğinden bahsetmektedir. Pers kostümü içerisinde kısa ve kemerli tunikli, kısa pelerinli, nimbuslu ve elleri dua eder pozisyonda iki yana açık pozisyondaki Daniel Peygamber betimi Doğu üslubunu yansıtmaktadır. Bkz. George P. Majeska, "A Medallion of the Prophet Daniel in the Dumbarton Oaks Collection," Dumbarton Oaks Papers 28 (1974), 361-362, dipnot 9.

51 Yunanca yazıtın transkripsiyonu, Uzman Sanat Tarihçisi D. Markella Bakouri tarafından yapılmıştır. 

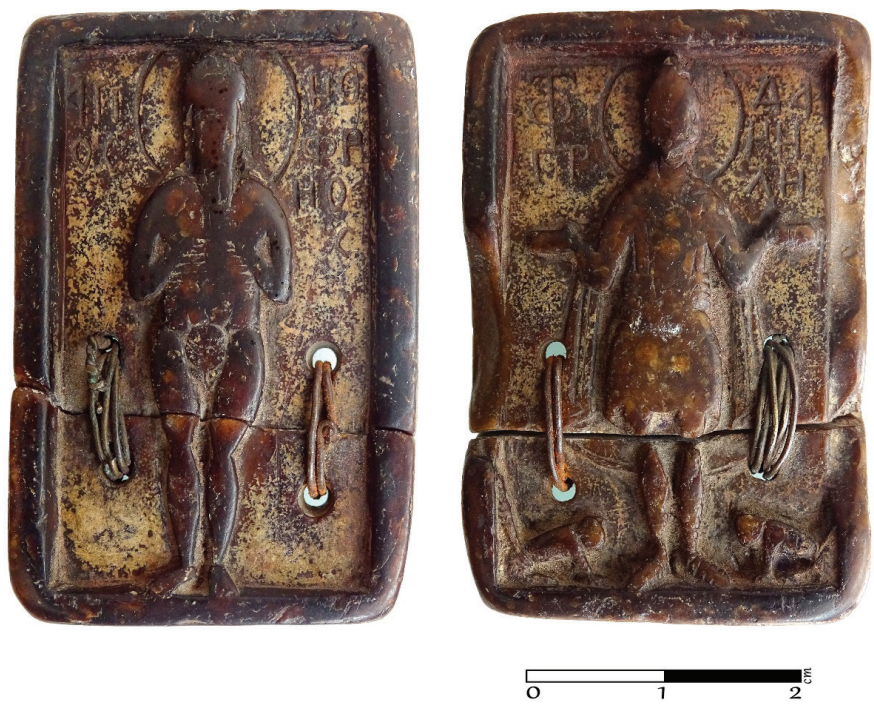

G. 3. Hematit Taşından Küçük İkona (12.-14. yüzy1l) Ön ve arka yüz (Müze env no. HPM 15573) (Merve Toy, 2019)

Hematit taşından ${ }^{52}$ yapılmış küçük ikonanın bir yüzünde tasvir edilen Aziz Onouphrios ve yaşamı hakkında günümüze ulaşan bilgiler, münzevi olarak Mısır'da çölde 1ssız bir yeri kendisine seçmiş olduğunu ve yaşamının sonuna kadar da buradan ayrılmadığını belirtmektedir. Kutsal günü 12 Haziran olan Aziz Onouphrios’un M.S. 400 civarında yaşamış olan bir münzevi olduğu bilinmektedir. Mısır'daki ünlü Teb şehri yakınlarında bulunan Hermopolis'deki bir manastırda keşiş olarak ruhani yolculuğuna çıktığı düşünülen Onouphrios, manastırdan ayrılıp 1ssız çölde inzivaya çekilerek altmış y1 $1^{53}$ kadar tek başına yaşamını sürdürmüş ve burada ölmüştür ${ }^{54}$.

Aziz Onouphrios, genellikle çıplak, oldukça uzun beyaz sakallı ya da tüm vücudu k1lla kaplı olarak tasvir edilmekte ve mahrem bölgeleri çöl bitkisi ile örtülü olarak görülmektedir ${ }^{55}$. Aziz Onouphrios erken dönemde yaşamış önemli bir kutsal kişi olmasına rağmen tasvirlerine Bizans'ın geç dönemlerinde daha sık rastlanmaktadır.

52 Hematit taşının Samos ve Lemnos adalarındaki kilden yapılmış tabletler ile aynı ilaç kategorisine girdiğini belirten B. Pitarakis yumuşak doku ve mide iltihaplanmalarına karşı etkili olduğunu, kanamayı dindirdiğini ve antibakteriyel özellikleri olduğunu anlatmaktadır. B. Pitarakis çalışmasında Lemnos adasında son zamanlarda jeologların yaptıkları analizlerin sonucunda kilin içerisinde kırmızı hematit pigmentinin olduğu bilgisini de vermektedir. Bkz. Pitarakis, "Şifayı Güçlendirmek Maddeler, Duyular ve Ritüeller," 173.

53 Ross, bir çalışmasında azizin altmış ya da yetmiş yıl boyunca çöllerde kaldığını (bkz. Ross, "Onuphrios," 657), bir başkasında ise bu sürenin yetmiş yıl olduğunu belirtmektedir. Bkz. Ross, "Onuphrius, Saint," 189; Paphnutius'un azizle olan karşılaşması ve sohbetini konu eden eserinde ise Onouphrius, kendi ağzından başrahibe altmış yıldır çölde olduğu bilgisini vermektedir. Paphnutius, Histories of the Monks of Upper Egypt and The Life of Onnophrius, 152.

54 Kazdhan ve Ševčenko, "Onouphrios," 1527.

55 Kazdhan ve Ševčenko, "Onouphrios," 1527; Christos Merantzas, "Bizans Kültüründe Benliğin Vücut Bulması”, Hayat Kısa, Sanat Uzun Bizans 'ta Şifa Sanatı (İstanbul: Pera Müzesi Yayınları, 2015),184, Şekil.2. 
Özellikle Bizans duvar resimlerinde 12. yüzyıldan itibaren yaygınlaşan azizin en ünlü betimlerinden biri Göreme Yllanlı Kilise'nin tonozu üzerinde görülebilir ${ }^{56}$. Burada yanındaki diğer iki azizle birlikte cepheden, elleri göğsü üzerinde ve orans pozisyonunda, mahrem yeri büyükçe bir palmiye yaprağıyla gizlenmiş olarak verilen azizin tasviri, hematit taşı ikonadaki betimine oldukça yakın bir üsluptadır. Azizin tasvirleri özellikle Bizans sonrası Rum ikonalarının da ilgi gören figürleri arasındadır ${ }^{57}$.
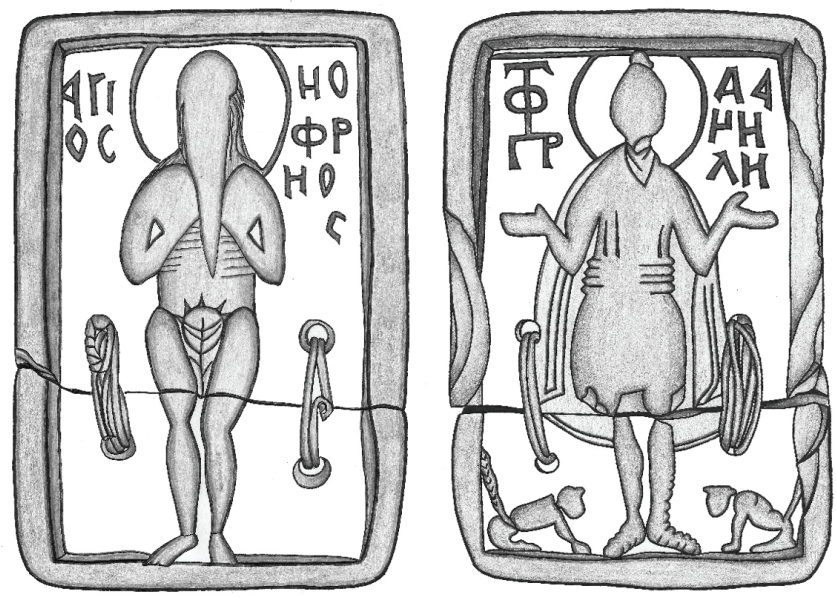

G. 4. Hematit Taşından Küçük İkona (12.-14. yüzyıl) Ön ve arka yüz çizimi (Çizim: Z. Çakmakçı)

İkonanın arka yüzünde betimlenen "Daniel aslan ininde" tasvirine ise Bizans sanatında sıkça yer verildiği bilinmektedir. Özellikle bu hikâye ile resmedilen madalyon, token, amulet gibi taşınabilir nitelikteki objeler genellikle Filistin'de azize ait olduğu ya da ona ithaf edildiği kabul edilen bir kutsal mekânla ilişkilendirilmektedir ${ }^{58}$. Bununla birlikte Filistin bölgesinde Peygamber Daniel'e ait kutsal bir mekân bilinmemektedir. Buna karşılık onun mezarının ve röliklerinin başkent Konstantinopolis'te Romanos Kapısı'nın yanında yer alan Aziz Romanos Kilisesi/Martyrion'unda muhafaza edildiği bilgisi dönem kaynakları tarafından dile getirilmektedir ${ }^{59}$. G. P. Majeska, Dumbarton Oaks Koleksiyonu'ndaki Daniel Peygamber tasvirli madalyon hakkındaki çalışmasında Konstantinopolis'in dini yaşamında Daniel'in mezarının çok önemli bir role sahip olmadığını ama Ortaçağ'ın ilerleyen dönemlerinde başkenti ziyaret eden hacılar tarafından hürmet duygusu ile ziyaret edildiğini ifade etmektedir. Yazar, ayrıca 12. ve 14. yüzyıllara ait belgelerde, Daniel Peygamber'in başkentteki kutsal mezarı

56 Marcel Restle, Die Byzantinische Wandmalerei in Kleinasien (Germany: Verlag Aurel Bongers, 1967), 1: 129-130; 2: resim no. 248.

57 Sercan Yandım, “Sinop Arkeoloji Müzesi’nde bulunan İkonalar,” 26. Araştırma Sonuçları Toplantısı (Ankara: T.C. Kültür ve Turizm Bakanlığı Yayınları, 2009), 2: 270.

$58 \mathrm{Bu}$ objelerle ilgili değerlendirme için bkz. Majeska, “A Medallion of the Prophet Daniel in the Dumbarton Oaks Collection," 362.

59 Majeska, “A Medallion of the Prophet Daniel in the Dumbarton Oaks Collection,” 363. 
hakkında bilgiler olduğunu da sözlerine eklemektedir ${ }^{60}$. Palaiologoslar Dönemi Rus gezginlerinin ifadesine göre Daniel Peygamber' in tasvirinin yer aldığı ve eulogia işlevindeki token ya da madalyonların, hac ziyaretini gerçekleştiren hacılar tarafından satın alındığına dair günümüze ulaşan kaynaklar da bulunmaktadır ${ }^{61}$. Palaiologoslar Dönemi'nde başkent Konstantinopolis'in dini yaşamında önemli bir konumda olduğu anlaşılan Daniel Peygamber'in kutsal mezarı ve burayı ziyaret eden hacıların aldıkları eulogia işlevindeki madalyon, token ya da küçük ikonalar ise Haluk Perk Müzesi'nde yer alan küçük hematit ikonanın tarihlendirilmesi konusunda yardımcı olmaktadır ${ }^{62}$. İkonanın üretim tarihi hakkında net bir bilgi olmamakla birlikte 12.-14. yüzyıllar arasına tarihlenebileceği düşünülmektedir.

\section{Sabuntaşından (Steatite) Küçük İ́kona - Aziz Nikholaos (11. - 13. yüzyll ?)}

Envanter No: HPM 15572

Yükseklik: $3.1 \mathrm{~cm}$, Genişlik: $3.5 \mathrm{~cm}$, Kalınlık: $0.55 \mathrm{~cm}$

Sabuntaşı (steatite) ikonanın ${ }^{63}$ üst kısmı kırık ve noksandır. Sağ eli takdis işareti yaparken; sol eli, üzerinde haç bulunan kutsal bir kitap taşır. Figürün sağ omuz başına yakın olarak Yunanca alt alta verilmiş KO / $\Lambda$ A harfleri okunmaktadır (G. 5).

Kutsal bir kişiye ait bu betimin kostümü incelendiğinde, öncelikle Aziz Nikholaos'un tasvirlerinde sikl1kla görülen piskoposluk giysisi olan omophorion dikkat çekmektedir. Sabuntaşı (steatite) ikonada betimlenen figürün üzerindeki kostüm tipi ve yazıtın günümüze ulaşan bölümü, tasvirin Aziz Nikholaos'a ait olduğunu göstermektedir ${ }^{64}$. Sabuntaşının (steatite) fildişi kullanımının sona ermesinden sonra en yakın malzeme olarak tercih edildiği bilinmektedir. Özellikle Bizans sanatında fildişinin yerini alan sabuntaşının (steatite) 11. yüzyıldan sonra yaygın olarak kullanıldığg

60 Ayrıntılı bilgi için bakınız Majeska, "A Medallion of the Prophet Daniel in the Dumbarton Oaks Collection," 363-364, dipnot 12 ve 14

61 Majeska, "A Medallion of the Prophet Daniel in the Dumbarton Oaks Collection," 366.

62 Benzer örnekler için bkz. Mine Kiraz, "Koruyucu Göğüs Pandantifi (enkolpion)," Hayat Klsa, Sanat Uzun Bizans 'ta Sifa Sanatı (İstanbul: Pera Müzesi Yayınları, 2015), 363, kat. no. 119; Majeska, "A Medallion of the Prophet Daniel in the Dumbarton Oaks Collection," 361-366; Alice Bank, Byzantine Art in the Collection of Soviet Museums (New York: Harry N. Abrams 1978), 304, Kat. 173; V. Phoskolou, "Jasper Cameo with Daniel in the Lion's Den," Everyday Life in Byzantium, ed. D. Papanikola-Bakirtzi (Athens: Hellenic Ministry of Culture, 2002), 516, kat. no. 713; İkonanın The Walters Sanat Müzesi'nde yer alan 13-14. yüzyıla tarihli sabuntaşından (steatite) yapılmış benzeri için bkz. https://art.thewalters.org/detail/8725/crucifixionwith-daniel-in-the-lions-den /, erișim 30 Aralık 2019; Metropolitan Sanat Müzesi’ndeki 1200 ve sonrasına tarihlenen serpantinden oyulmuş yakın bir benzeri için bkz. https://www.metmuseum.org/toah/works-ofart/1987.442.4/, erișim 30 Aralık 2019.

63 Bizans sanatı örnekleri incelendiğinde sabuntașı (steatite) ikonaların oldukça küçük ebatta olmalarından dolayı kișisel ya da aileye ait șapellerde kullanılmıș oldukları düșünülmektedir. Bkz. Gary Vikan, "Steatite," Oxford Dictionary of Byzantium, (New York: Oxford University Press, 1991), 3: 1947.

64 Ayrıntılı bilgi için bkz. Alexander Kazdhan ve Nancy Peterson Ševčenko, "Nicholas of Myra," Oxford Dictionary of Byzantium, (New York: Oxford University Press, 1991), 2: 1469-1470. 
görülmektedir ${ }^{65}$. Bu anlamda sabuntaşından (steatite) küçük ikona, 11.- 13. yüzyıl arasında üretilmiş olmalıdır ${ }^{66}$.
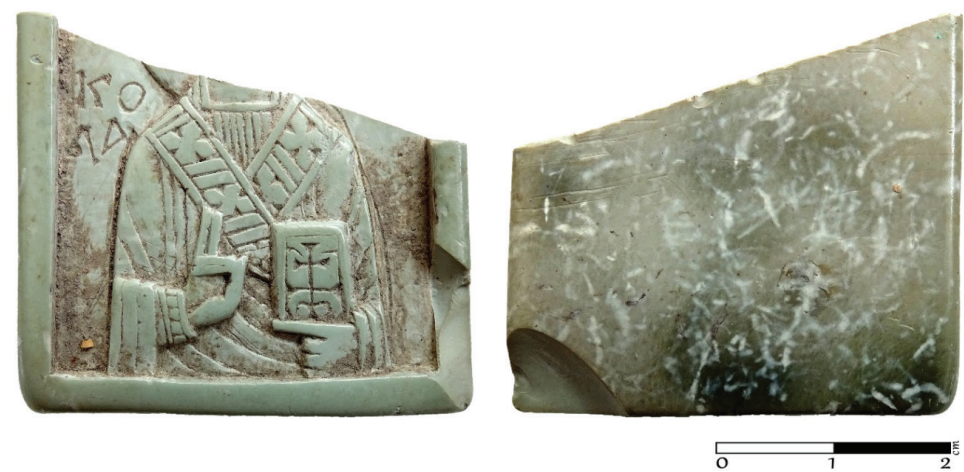

G. 5. Sabuntaşından (Steatite) İkona- Aziz Nikholaos (11-13. yüzyıl ?) Ön ve arka yüz (Müze env no. HPM 15572 (Merve Toy, 2019)

Bizans sanatında sık kullanılan bir figür olan Aziz Nikholaos, madalyon, cameo ve sikke gibi küçük el sanatı objelerde yaygın olarak betimlenmiştir. Özellikle 10 . yüzyılın ikinci yarısında başlayıp, 11. yüzyıl boyunca üretilen kurşun mühürler üzerinde karşılaşılan zengin ikonografi içinde en popüler tasvirin Aziz Nikholaos olduğu görülmektedir ${ }^{67}$. Azizin betimi, 11. yüzyıl ortas1-12. yüzyıldan itibaren ikona sanatında görülen canlanmayla birlikte, martir olan ve mucizeleri ile nam salmış azizlerin hayatını anlatan Vita ikonalarına da yansımış ve Aziz Nikholas bu dönemden itibaren Vita ikonalarında en çok tasvir edilen azizlerden biri hâline gelmiştir ${ }^{68}$. Denizcilerin, çocuk ve kadınların koruyucusu olarak hürmet gören Aziz Nikholaos Anadolu'nun en önemli azizlerindendir ${ }^{69}$.

65 A. Cutler, Bizans dünyasında sabuntaşı (steatite) kullanımının 10. yüzyıldan önceye gitmediğine dair düşüncenin tartışlabileceğinden bahsetmektedir. Antony Cutler, "Ivory, Steatite, Enamel, and Glass," The Oxford Handbook of Byzantine Studies, ed. E. Jeffries, R. Cormack ve J. Haldon (Oxford: Oxford University Press, 2008), 456-457; Bizans İmparatorluğu'nun fildişi kaynağı olan Kuzey Afrika topraklarını Araplara, Doğu Akdeniz ticaretini ise İtalyan devletlerine kaptırmasıyla, hammadde olarak filldişini elde etmesi güçleşir. Sabuntaşının (steatite) kolay işlenebilir olmasına ek olarak fildişine benzerliği ve ayrıca doğal bir hammadde olarak kolay bulunması dolayısıyla Bizans dünyasında çok sık kullanılan bir malzeme hâline geldiği bilinmektedir. Bizans kaynaklarında amiantos lithos olarak kayda geçtiği bilinen sabuntaşı (steatite) rengine dair herhangi bir bilgi olmamakla birlikte günümüze ulaşan örneklerinden soluk yeşil bir renge sahip olduğu anlaşılmaktadır. Bkz. Cutler "Ivory, Steatite, Enamel, and Glass," 457.

66 Benzer örnekler için bkz. Charalambos Bakirtzis, "Small Steatite Icon of St Nicholas," ed. D. PapanikolaBakirtzi, Everyday Life in Byzantium (Athens: Hellenic Ministry of Culture, 2002), 159, kat. no.180; Yannis D. Varalis, "Steatite Icon of St Nicholas," Everyday Life in Byzantium, ed. D. Papanikola-Bakirtzi (Athens: Hellenic Ministry of Culture 2002), 159-160, kat. no.181.

67 John Nesbitt, "Sigillography," The Oxford Handbook of Byzantine Studies, ed. E. Jeffreys, J. Haldon ve R. Cormack, (Oxford: Oxford University Press, 2008), 153.

68 Maria Vassilaki, "Icons," The Oxford Handbook of Byzantine Studies, ed. E. Jeffreys, J. Haldon ve R. Cormack, (Oxford: Oxford University Press, 2008), 765.

69 Helen Evans ve William D. Wixcom, The Glory Of Byzantium, Art and Culture of the Middle Byzantine Era A.D. 843-1261 (New York: The Metropolitan Museum of Art, 1997), 499, Kat. no. 336. 


\section{Pandantif /Enkolpion (10.-12. yüzyıl ?)}

Envanter No: HPM 15571

Çap: $2,5 \mathrm{~cm}$
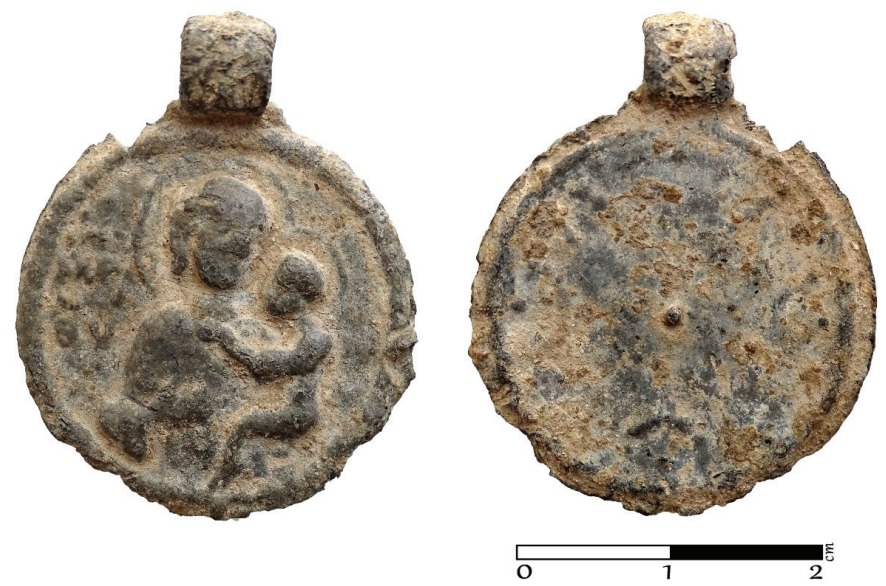

G. 6. Pandantif (enkolpion) (10.-11. yüzyıl ?) Ön ve arka yüz (Müze env no. HPM 15571) (Merve Toy, 2019)

Ön yüz: Oldukça aşınmış durumdaki madalyonun ön yüzünde Meryem Hodegetria tasviri bulunmaktadır (G. 6). Sol kolunda taşıdığı çocuk İsa'yı, sağ eli ile işaret eden Meryem, insanoğluna kurtuluşa giden yolun İsa'nın öğretisinden geçtiğini vurgulamaktadır. Madalyonun sol tarafında sütun sıralı hâlde ve alt alta Meryem'in adının kısaltması olan MP @V (Tanrı Anası) siglasına yer verilmiştir. Pandantifin (enkolpion) üzerinde asılarak kullanılmasına yönelik bir kulp halkası bulunur. Yol Gösteren anlamına gelen Hodegetria unvanlı tasvirin gelişim süreci oldukça eskiye dayanmaktadır.

Arka yüz: Belirsiz.

Meryem Hodegetria tasviri, Hagia Sophia'nın doğusunda, denize doğru bir yamaçta yer alan Hodegon Manastırı'yla ilişkilendirilir. İmparator II. Theodosius'un kızkardeşi Pulcheria (399-453) tarafindan kurulduğu söylenen bu manastırın, sonraları İncil yazarlarından Aziz Lukas tarafından betimlendiği düşünülen ve Meryem Hodegetria olarak nam salmış ünlü ikonanın korunduğu yer olarak da adı geçmektedir. Hodegon Manastırı'nın 9. yüzyılda aktif olduğu, 12. yüzyılda da tadilat gördüğü bilinmektedir. Manastırın "Yol Gösteren" anlamındaki ismini burayı ziyarete gelen kör hacıları mucizevi şifalı kaynağa götüren rahiplerinden aldığı anlaşılmaktadır ${ }^{70}$.

70 Cecily Hennessy, “Topography of Constantinople," The Oxford Handbook of Byzantine Studies, ed. E. Jeffreys, J. Haldon ve R. Cormack (Oxford: Oxford University Press, 2008), 211. 


\section{Pandantif/Enkolpion (11.-14. yüzyıl)}

Envanter No: HPM 15570

Çap: $3,8 \mathrm{~cm}$

Ön yüz: Pandantifin (enkolpion) ön yüzünde dekoratif çerçeveli bir madalyon içinde Meryem Deksiokratousa tasviri yer almaktadır. Meryem'e atfedilen ve omuzlarının iki yanına istiflenmiş Tanrı anası (MP $\Theta V$ ) anlamına gelen siglası ise ters olarak $\mathrm{V} \Theta \mathrm{MP}$ şeklinde basılmıştır. Kalıp baskısı hazırlanırken, yazıt yanlışlıkla ters olarak yerleştirilmiş olmalıdır (G. 7).

Arka yüz: Pandantifin (enkolpion) arka yüzünde inci bordürlü bir madalyon içinde, yarım boy hâlinde ve cepheden verilen figürün bir asker aziz olduğu açıktır. Yazıtı olmaması ya da var olan yazıtının zamanla tahrip olması nedeniyle figürün kimliği tanımlanamamaktadır. Bununla birlikte bu tasvirin kısa kıvırcık saçlı ve zırh kostümlü genç erkek betimiyle Aziz Georgios ${ }^{71}$ 'u temsil ettiği düşünülmekte, ancak yine de kimliği tartı̧̧maya açık bırakılmaktadır. Genellikle kısa kıvırcık saçlı genç erkek betimiyle resmedilen Aziz Panteleimon'un da Aziz Georgios'a benzer tasvirleri bulunmakla birlikte, zırhı ve kostüm detayları dolayısıyla askeri vasıfları ile öne çıkan Aziz Georgios'un madalyonun üzerinde betimlenmesinin daha kuvvetli bir ihtimal olduğu varsayılmaktadır.

Sağ kolunda taşıdığı çocuk İsa'yı, sol eli ile işaret eden Meryem betimi Bizans sanatında Deksiokratousa olarak tanımlanmaktadır ${ }^{72}$. 11. yüzyıldan itibaren ikonografiye girdiği bilinen Deksiokratousa tasvirine sık rastlanmamaktadır. Bu tasvir tipi, Meryem Hodegetria ${ }^{73}$ betiminin bir varyasyonu olarak ortaya çıkmış, ama Hodegetria kadar popüler olmamakla birlikte farklı eser gruplarında yer almıştır ${ }^{74}$.

71 Alexander Kazdhan ve Nancy Peterson Ševčenko, “George," Oxford Dictionary of Byzantium (New York: Oxford University Press, 1991), 1: 834-835.

72 Nancy Peterson Ševčenko, "Virgin Hodegetria," Oxford Dictionary Byzantium (New York: Oxford University Press, 1991), 3: 2172.

73 Hodegetria betiminin en erken örnekleri 7. yüzyıla tarihlenen imparatorluk mühürlerinde bulunmaktadır. Bkz. Bissera V. Pentcheva, “The 'activated' Icon: The Hodegetria Procession and Mary’s Eisodos,” Images of the Mother of God, ed. M. Vassilaki (Norfolk: Ashgate Publishing, 2005), 196; John Nesbitt, Catalogue of Byzantine Seals at Dumbarton Oaks and in the Fogg Museum of Art (Washington D.C.: Harvard University Press, 2009), 6:54, kat. no. 24.1; 6:57-58, kat.no. 27.2-28.1; Hodegetria tasviri ve ikonaları ile ilgili daha detaylı bilgi için bkz. Bissera V. Pentcheva, Icons and Power: The Mother of God in Byzantium (Pennsylvania: Pennsylvania State University Press, 2006), 109-143; Annemarie Weyl Carr, "Icons and The Object of Pilgrimage In Middle Byzantine Constantinople," Dumbarton Oaks Papers 56 (2002), 80-81.

74 B. Pitarakis, sağ kolunda çocuğunu taşıyan Meryem'in tam boy tasvirinin yer aldığı mühür hakkında bilgi vermektedir. 12. yüzyıla ait mühür, büyük bir arzu ile istemelerine rağmen çocuk sahibi olamayan Irene Synadene ve Manuel Botaneiates'e aittir. Yazar, çiftin çocuk sahibi olma arzusu ile Meryem'in lütfuna sığındıklarından, kişisel kullanımlarında olan enkolpionda olduğu gibi bu dileklerini mühür tasvirine de yansittıklarından bahsetmektedir. Bkz. Brigitte Pitarakis, "Female Piety in Context," Images of the Mother of God, ed. M. Vassilaki (Norfolk: Ashgate Publishing, 2005), 158, 166, Kat. no. 13.9. 

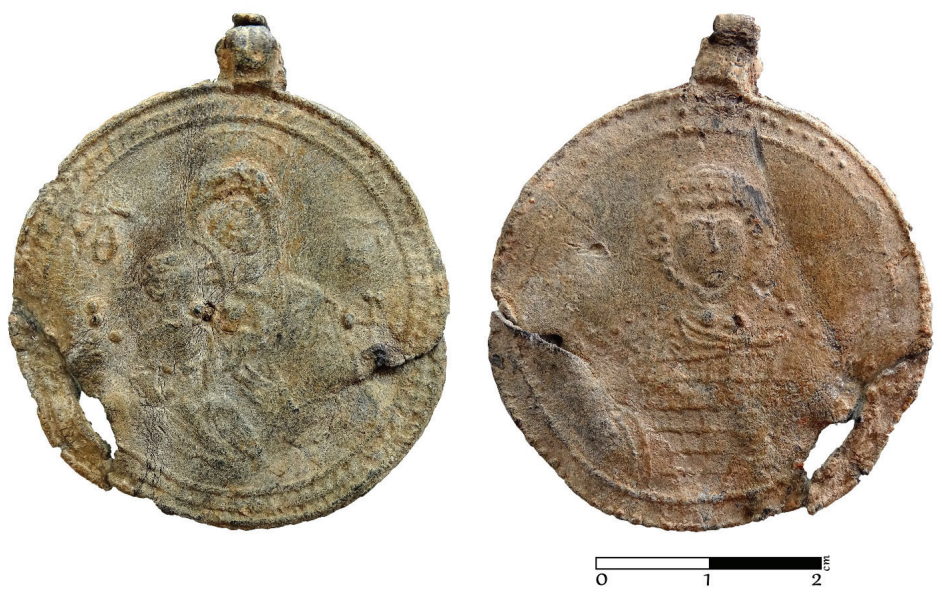

G. 7. Pandantif (enkolpion) (11.-12. yüzyıl) (Müze env no. HPM 15570) (Merve Toy, 2019)

\section{Pandantif/Enkolpion (11.- 13. yüzyıl (?)}

Envanter No: 3709 HPM 11589

Çap: $2,9 \mathrm{~cm}$

Ön yüz: Pandantifin (enkolpion) ön yüzünde tam boy ve cepheden verilmiş Meryem Blakhernitissa tasviri bulunmaktadır ${ }^{75}$. Dıştan yuvarlak bir madalyon içine alınan figürün yüz detayı anlaşılmamakta, bununla birlikte kostümü ve hareketleri ayrıntıyla tanımlanabilmektedir (G. 8). Meryem ayak bileklerine kadar uzun tuniği ve bedeninin üst bölümüne doladığı kollarından aşağıya uçları sarkan peleriniyle dua pozisyonunda tasvir edilmiştir.
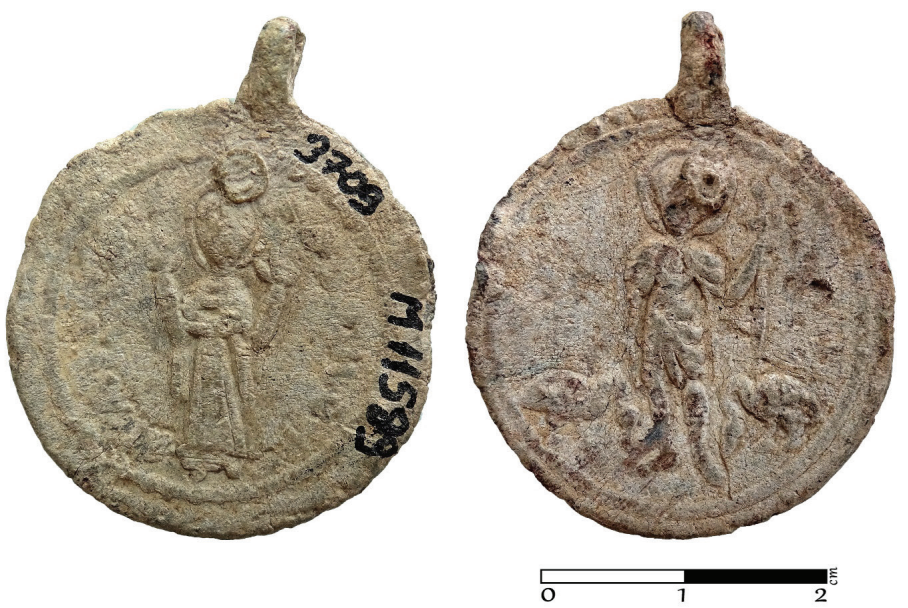

G. 8. Pandantif (enkolpion) (11.-13. yüzy1l) (Müze env no. HPM 15589) (Merve Toy, 2019)

75 Ayrıntılı bilgi için bkz. Nancy Peterson Ševčenko, "Virgin Blachernitissa," Oxford Dictionary of Byzantium (New York: Oxford University Press, 1991), 3: 2170-2171. 
Arka yüz: Eserin arkasında tam boy ve cepheden verilmiş, sol elinde kılıç taşıyan bir aziz yer almaktadır. Kısa tuniği ve peleriniyle verilmiş bu azizin ayaklarının iki yanında yemlenir hâlde birer kaz betimlenmiştir. Tasvirde görülen kazlar, resmedilen figürün Aziz Tryphonos olduğunu düşündürmektedir. Bizans İmparatorluğu'nda hürmet gören bir kişi olan Aziz Tryphonos'un gençliğinde kaz çobanı olduğu rivayet edildiği için tasvirlerinde de etrafındaki kazlarla birlikte betimlendiği görülür. Bununla birlikte aziz, kimi zaman bağların koruyucusu olarak elinde bağ bıçağı ile de resmedilmektedir. Azizin madalyon dışında İznik İmparatorluğu'nun hami/koruyucu azizi olarak sikkelerde de betimine rastlanır.

3. yüzyılda martir olan Aziz Tryphonos'un Phrygia bölgesindeki Lampsakus'ta (Lapseki) doğduğuna, erken yaşlarından itibaren Tanrı tarafından kendisine bahşedilen güçle türlü hastalıkları iyileştirdiğine ve şeytani güçleri uzaklaştırdığına inanılmaktadır ${ }^{76}$. Hatta köyündeki tarlalarda bulunan tahılın çekirge istilası yüzünden yok olması sonucunda ortaya çıkan kıtlıktan halkını kurtardığ yönünde anlatılar da vardır. Hakkındaki en önemli söylenti ise İmparator Gordianus'un (M.S. 238-244) kızını sağlığına kavuşturmasıdır. Azizin ruh hastalığı tıp doktorları tarafından iyileştirilemeyen imparatorun kızını tedavi ettikten sonra saraydan kendisine gönderilen hediyeleri fakir halkla paylaştı̆̆ söylenir. Hristiyan inananlar İmparator Decius'un (M.S. 249-251) iktidarı sırasında ağır cezalar ve zulüm ile karşılaşmıştır. Aziz Tryphonos da Roma imparatoru Decius döneminde türlü işkenceler gördükten sonra öldürülmüş, daha sonra da martir aziz olarak hürmet görmüştür ${ }^{77}$. 250 yılında Nikaia şehrinde ağır işkence görerek öldürüldüğü söylenen azizin, Hristiyan inananlar tarafından bedeni temiz bir kefene sarılarak gömülmeye götürüldüğü sırada topluluğa göründüğü ve bu esnada doğduğu yerde gömülmek istediğini söylediği anlatılır. Böylece ilk önce Lampsakus'a gömülmüş ${ }^{78}$, daha sonra naaşı Konstantinopolis'e ve son olarak da Roma'ya taşınmıştır. Azizin tezahür ettiği 1 Şubat tarihinde İznik'teki kilisesinde tören düzenlenmektedir. Sabah hizmetinden sonra çok geniş katılımlı bir kalabalık önünde aziz için hürmet ilahileri söylenirken, azizin lambasına koyulan kuru zambak çiçeği soğanının mevsimi dışında, dondurucu soğuk içerisinde aniden çiçek açtığı mucizesine şahit olunmaktadir ${ }^{79}$. İznik İmparatorluğu'nun başkentinde her yıl gerçekleşen mucizesi, büyük bir coşku ile izlenmektedir. Rus kültüründe Aziz Tryphonos, kuşların hami azizi olarak kabul edilir. Rus Ortodoks Kilisesi'nde büyük bir hürmet gören azizin aynı zamanda Moskova'nın da koruyucusu olduğuna inanılmaktadır. İznik İmparatorluğu'nun da hami azizi olarak kabul edilen Tryphonos'un tasviri ve atribüsü olan süsen çiçeği betimi sikkelerde de karşımıza çıkmaktadır.

76 Clive Foss, "Pilgrimage in Medieval Asia Minor," Dumbarton Oaks Papers 56 (2002), 142; John Osborne, "Politics, Diplomacy and The Cult of Relics in Venice and The Northern Adriatic in The First Half of The Ninth Century," Early Medieval Europe 8/3 (1999), 379, dipnot 49.

77 Foss, "Pilgrimage in Medieval Asia Minor," 142.

78 Foss, "Pilgrimage in Medieval Asia Minor," 142.

79 Foss, "Pilgrimage in Medieval Asia Minor," 142. 


\section{7. Üç Adet Bronz Obje (12.-14. yüzyıl)}

7a. Envanter No. HPM 15568.

Ölçüler: $3.2 \times 2.4 \mathrm{~cm}$

Ön yüz: Ön yüzde yuvarlak bir madalyonla çevrelenmiş, sekiz adet taç yapraktan oluşan rozet biçimli bitkisel bir motif yer alır (G. 9). Yapraklardan diyagonal yerleştirilenler üçgen; diğerleri oval biçimlidir. Yaprakların arasında kalan boşluklar nokta biçimli bezemelerle doldurulmuş, yaprakların dış konturları da birbirini takip eden nokta bezemelerle yapılmıştır. Bu motifi bitkisel motif ile stilize edilmiş bir haç olarak yorumlamak da mümkündür.
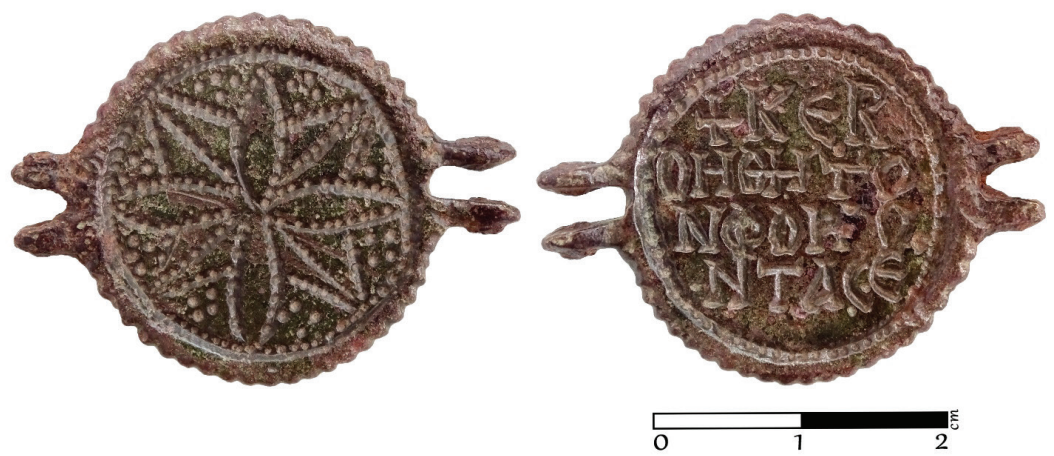

G. 9. Bronz obje (12.-14. yüzy1l) (Müze env no. HPM 15568) (Merve Toy, 2019)

Arka yüz: Objenin arkasında madalyon içine alınmış paralel dört sıra hâlinde Yunanca bir yardım yazıtı yer almaktadır. Madalyonların her iki yanında da başka madalyonlara ya da halkalara eklenmeleri için yapılmış menteşeler bulunur. Ancak menteşelerin mil kısımları noksandır.

\section{Yazit:}

+ K[YPI $\}$ E (Tanrım)

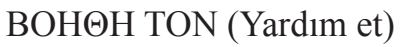

ФOPONTA CE (Fronta)

(Tanrım Fronta'ya yardım et)

7b. Envanter No. HPM 15569.

Ölçüler: $3.6 \times 2.4 \mathrm{~cm}$

Ön yüz: Yuvarlak bir madalyon içine alınmış ön yüzde yarım boy ve cepheden verilmiş İsa tasviri yer alır. Oldukça şematize olarak çizilmiş figürün sağ eliyle takdis 
işareti yaptığı görülmektedir. Omuzlarının iki yanında İsa'nın adının kısaltması olan IC XC siglası yer alır (G. 10).

Arka yüz: Bu yüzde yuvarlak madalyon içinde yarım boy ve cepheden Meryem tasvirine yer verilmiştir. Meryem orans pozisyonunda elleri iki yana açık ve son derece şematik olarak işlenmiştir ${ }^{80}$. Objenin her iki yanında bir başka madalyona ya da halkaya bağlanması için yapılmış menteşeler bulunur. Bunlardan birinin mil kısmı tahrip olmuşken, diğerinde bağladığı halkanın kırık bir ucu görülebilmektedir.
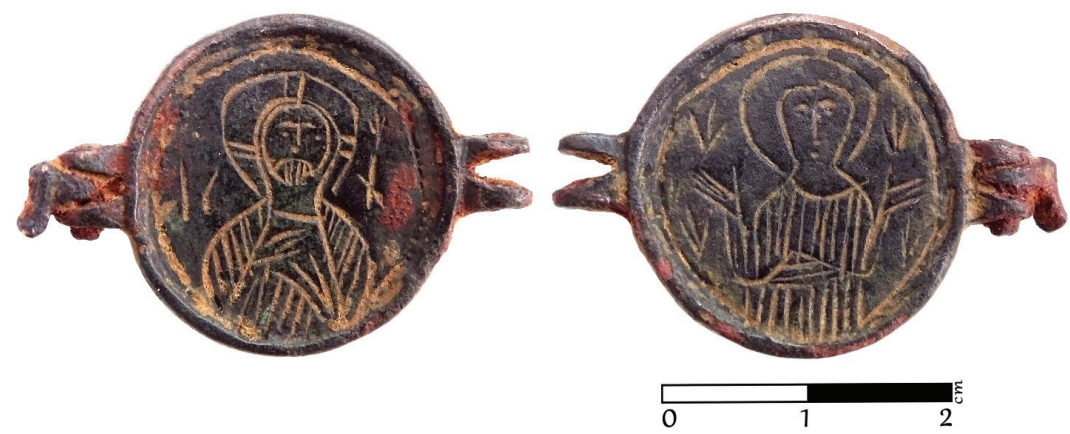

G. 10. Bronz obje (12.-14. yüzy1l) (Müze env no. HPM 15569) (Merve Toy, 2019)

7c. Envanter No. HPM 15567.

Ölçüler: $4 \times 2 \mathrm{~cm}$

Ön yüz: Yuvarlak madalyon içinde orans pozisyonunda elleri iki yana açık, cepheden ve yarım boy verilmiş Meryem yer alır (G. 11).

Arka yüz: Bu yüzde yuvarlak madalyon içinde paralel dört sıra ile istiflenmiş Yunanca bir yardım yazıtı bulunmaktadır. Objenin her iki yanında bulunan bağlantı menteşeleri sağlamdır. Bunlardan biri üzerinde başka bir zincir, madalyon ya da halkaya eklenmesi için yapılmış yuvarlak bir halka tam ve sağlam olarak korunmuştur.

\section{Yazit:}

$+\mathrm{K}[\mathrm{YPI}\} \mathrm{E}$ (Tanrım)

$\mathrm{BOH} \Theta \mathrm{H}$ (yardım et)

$\Theta \mathrm{EO} \Lambda \mathrm{O}[\ldots]$ (Theolo (?))

YANH

(Tanrım Theolo(?)'ya yardım et)

80 Meryem Blakhernitissa. 
Bu üç adet küçük boyutlu ve her iki yüzünde kutsal tasvir, motif ya da dua yazıtı içeren daire formlu bronz objelerin iki yanlarında bağlayıcı halka aparatlar bulunmak$\operatorname{tad}_{11}{ }^{81}$. Bu objelerin tam formları kesin olarak bilinmemekle birlikte bilezik, kolye, kemer ya da pandantif parçaları olduğu düşünülmektedir.

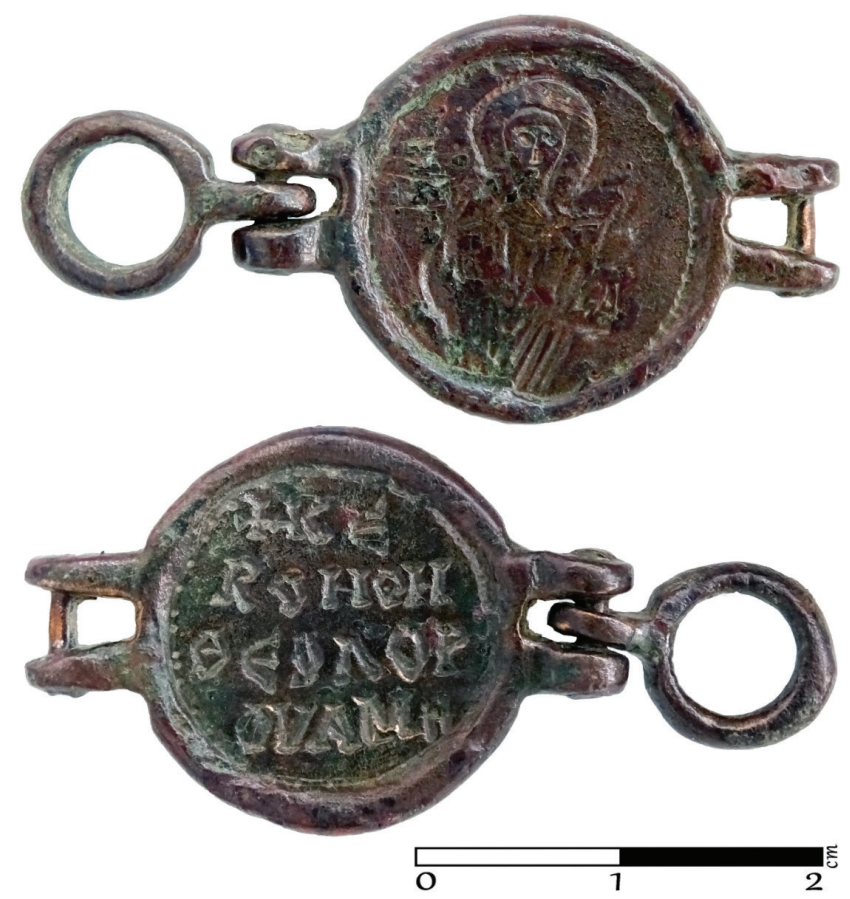

G. 11. Bronz obje (12.-14. yüzyı1) (Müze env no. HPM 15567) (Merve Toy, 2019)

Özellikle Figür 7c'nin (G. 11) bir yanında sağlam olarak korunmuş halka, bunların başka madalyon ya da halkalar eklenerek bilezik, kolye, kemer ya da pandantif olarak kullanıldıkları düşüncesini desteklemektedir. Benzer objeler ile ilgili ulusal ve uluslararası kaynaklarda örneklere sıklıkla rastlanmamaktadır ${ }^{82}$. Bu bakımdan oldukça ilgi çekici örnekler oldukları açıktır. Ön ve arka yüzlerinde yer alan İsa ve Meryem figürlerinin yanı sıra bitkisel bezeme ile dizayn edilmiş haç motifi ve dört sıralı dua, dilek yazıtı koruyucu işleve sahip olduklarını göstermektedir. Bunların Bizans İmparatorluğu dönemine ait ve günlük yaşamı yansıtan dini objeler oldukları anlaşılmaktadır. Bu küçük, her iki yüzünde kutsal birer tasvir ya da motif ve dua yazıtı içeren dairesel formlu objeler inanan kişinin günlük yaşamında üzerinde taşıdığı dini içerikteki aksesuarlardandır. Koruyucu niteliklerinden dolayı bu tür objelerin manastırları ziyaret eden

81 İki adet bronz obje üzerinde yer alan Yunanca yazıtın transkripsiyonu Uzman Sanat Tarihçi D. Markella Bakouri tarafindan yapılmıştır.

82 Benzer örnek için bkz. Christian Schmidt, "Gold- Silber- und Bronzeikonen," Die Welt von Byzanz-Europas Östliches Erbe (München: Theiss, 2004), 181, 231. 
dindar Hristiyanlar tarafından hatıra olarak alınmış oldukları düşünülebilir. Ortaçağ'da Bizans dünyasında egemen olan yoğun ruhani destek ve koruma arayışının farklı örneklerinden olan üç adet obje, günümüze ulaşan nadir örneklerdendir. Yapım tarihleri tam olarak bilinmemekle birlikte Geç Bizans dönemine ait olma ihtimalleri yüksektir.

Figür 7a'da (G. 9) sunulan objenin bir yüzünde bitkisel bezeme ile formüle edilerek oluşturulan haç motifi yer alırken diğerinde dört sıralı dua yazıtı bulunmaktadır. Figür 7b’nin (G. 10) ön yüzünde oldukça çizgisel bir üslupta yapılmış olan Pantokrator İsa diğer yüzünde ise Meryem Blakhernitissa betimleri vardır. Objedeki tasvirlerin çizgisel üslubu, 14. yüzylla ait sikke betimleriyle de örtüşmektedir ${ }^{83}$. Son olarak, daha özenli bir üslupla yapıldığ anlaşılan Figür 7c'nin (G. 11) ön yüzünde Meryem Blakhernitissa ve arka yüzünde dua yazıtı yer alır.

\section{Pandantif/Enkolpion (12.-14. yüzyıl)}

8a. Envanter No. HPM 15578.

Ölçüler: $3.1 \times 2.8 \mathrm{~cm}$

Ön yüz: Yonca biçimli pandantifin (enkolpion) ortasında yuvarlak bir madalyon içinde, elleri iki yana açık, orans pozisyonunda Meryem büstü yer alır (G. 12).

Arka yüz: Nokta dizileriyle çevrili yuvarlak madalyonun ortasında uçları genişleyerek açılan bir haç motifine yer verilmiştir. Haçın kolları eşit uzunluktadır. Pandantifin (enkolpion) yonca biçiminde dışaçıkıntı yapan yarım yuvarlak bölümleri içine ayrıntıları net olarak seçilmeyen bitkisel karakterli bir bezeme yapılmıştır. Objenin asılma halkası zamanla koptuğu ya da tahrip olduğu için en üste kalan yarım yuvarlak çıkıntı içine delik açılmış ve obje olasılıkla bu hâliyle kullanılmaya devam etmiştir.
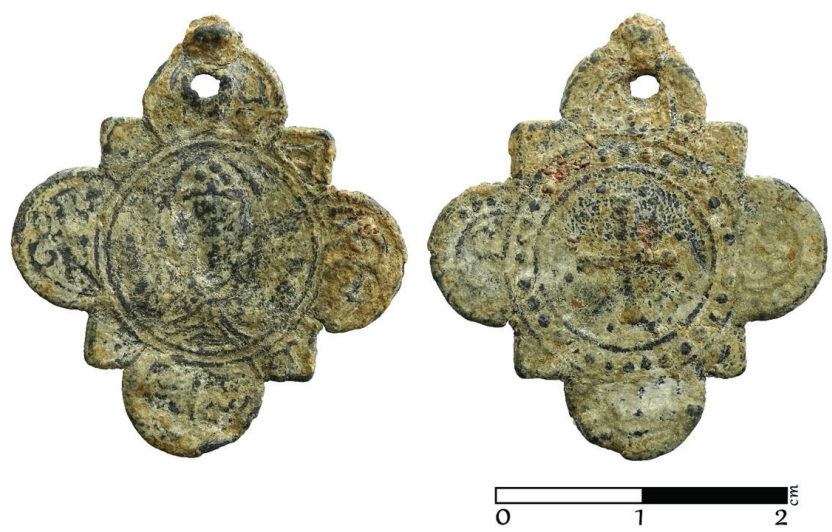

G. 12. Pandantif (enkolpion) (12.-14. yüzyıl) Ön ve arka yüz (Müze env no. HPM 15578)

(Merve Toy, 2019)

83 Eleni Lianta, Late Byzantine Coins 1204-1453 (London: Spink Books, 2009), 277-325; Philip Grierson, Byzantine Coins (California: University of California Press, 1982), 385, Plate 95. 
8b. Envanter No. HPM 15579

Ölçüler: $3.1 \times 2.8 \mathrm{~cm}$
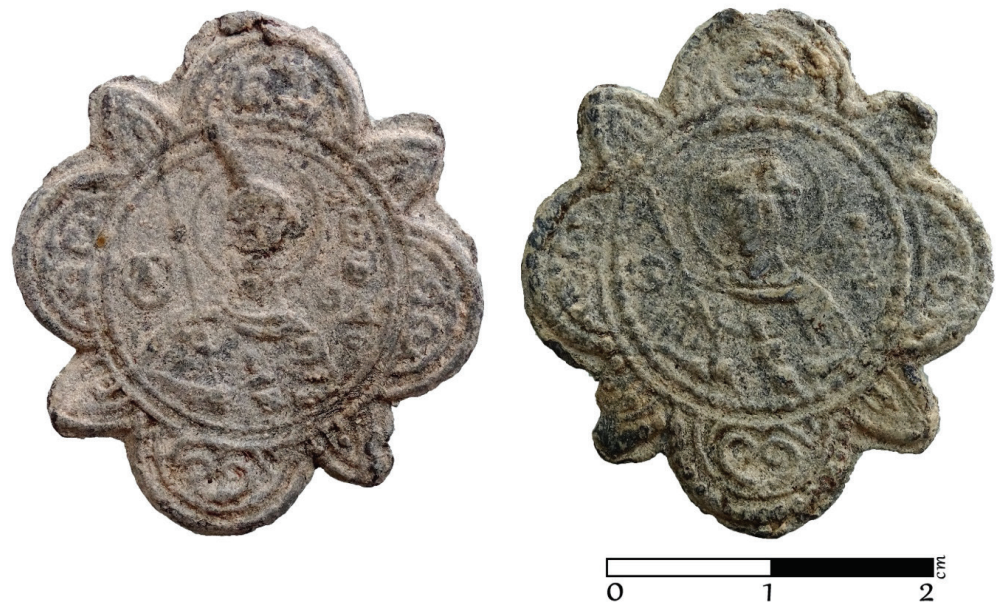

G. 13. Pandantif (enkolpion) (12.-14. yüzyıl) Ön ve arka yüz (Müze env no. HPM 15579) (Merve Toy, 2019)

Ön yüz: Bu yüzde kısa saç modeli ve kostümü dolayısıyla Aziz Georgios (?) olabileceğini düşündüğümüz bir asker aziz betimlenmiştir. Sağ elinde mızrak, sol elinde kınında kılıç taşıyan aziz yarım boy ve cepheden tasvir edilmiş ve yuvarlak bir madalyon içine alınmıştır. Solda aziz monogramı yer alırken, sağda silinerek netliğini kaybetmiş bir yazıt bulunur (G. 13). Yonca biçimli pandantifin (enkolpion) dışa taşkın yuvarlak bölümleri kıvrım dallardan oluşan bitkisel bir bezeme ile doldurulmuştur.

Arka yüz: Pandantifin (enkolpion) arka yüzünde yuvarlak madalyon içinde ve yarım boy ve cepheden verilmiş bir aziz tasviri yer alır. Azizin sağ elinde tuttuğu mızrak ile sol elinde kınında taşıdığı kılıç onun bir asker aziz olduğunu göstermektedir. Figürün sağında aziz monogram bulunmakta, sol tarafinda ise kimliğini tanımlayan sütun sıralı $\Theta-\mathrm{O} \Delta \mathrm{O}$ harflerinden oluşan Yunanca bir yazıt yer almaktadır. Yazıt betimlenen azizin asker azizlerden Theodoros ${ }^{84}$ olduğunu göstermektedir.

8c. Envanter No. HPM 15576

Ölçüler: $2.9 \times 2.9 \mathrm{~cm}$

Ön yüz: Yuvarlak madalyon içinde cepheden ve yarım boy olarak verilmiş figür sağ elinde mızrak, sol elinde kınında kılıç taşımaktadır (G. 14). Tasvirin yanındaki yazıt tahrip olduğu için kimliği anlaşılmayan bu azizin kostüm ve aksesuarlarından asker aziz olduğu ve muhtemelen Aziz Georgios'u (?) betimlediği düşünülmektedir.

84 Alexander Kazdhan ve Nancy Peterson Ševčenko, “Theodore Stratelates," Oxford Dictionary of Byzantium (New York: Oxford University Press, 1991), 3: 2047. 
Figürün sağ omuz başında aziz monogramı ve sol omuz başında ise silinerek tahrip olmuş yazıtı yer alır.

Arka yüz: Bu yüzde madalyon içinde sağ elinde mızrak, sol elinde kınında kılıç taşıyan asker bir azize yer verilmiştir. Figürün sol tarafinda net olarak okunan sütun sıralı $\Theta \epsilon O \Delta(\mathrm{O})$ harflerinden oluşan Yunanca yazıttan Aziz Theodoros olduğu anlaşılmaktadır. Sağ omuz başında da aziz monogramına yer verilmiştir. Yonca biçimli enkolpionun dışa taşkın yarım yuvarlak formlu kısımları bitkisel bezeme ile doldurulmuştur.
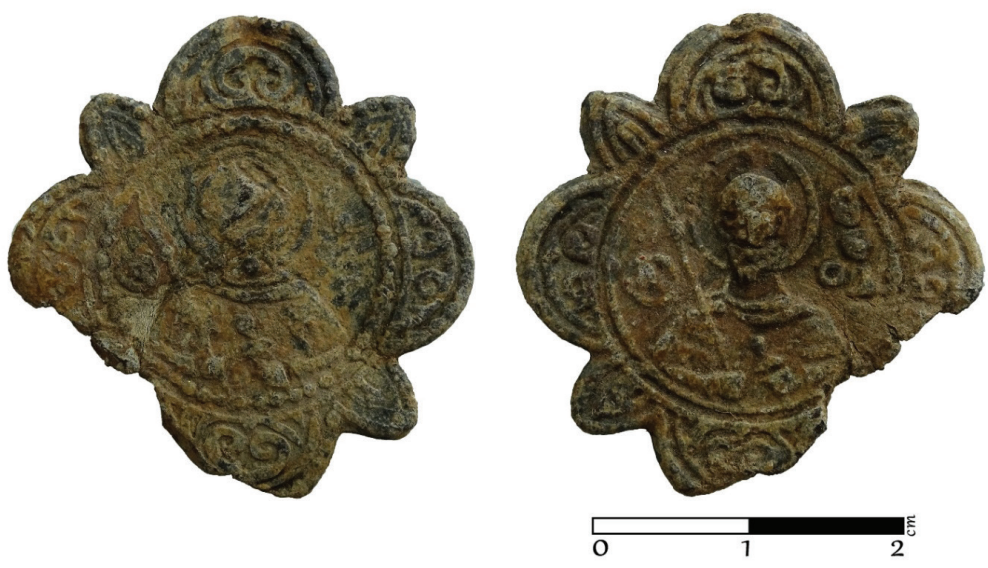

G. 14. Pandantif (enkolpion) (12.-14. yüzyıl) Ön ve arka yüz (Müze env no. HPM 15576) (Merve Toy, 2019)

8d. Envanter No. HPM 15575.

Ölçüler: $3.2 \times 2.8 \mathrm{~cm}$

Ön yüz: Pandantifin (enkolpion) ortasında yuvarlak madalyon ile çevrelenmiş, cepheden ve yarım boy verilmiş bir asker aziz yer alır (G. 15). Yazıtı ve yüz bölgesi oldukça tahrip olduğundan kimliği bilinemeyen azizin sağ elinde mızrak, sol elinde kınında kılıç taşıdığı anlaşılmaktadır. Figürün sağ omuz başında aziz monogramına yer verilmiştir.

Arka yüz: Ön yüzdekine benzer bir kompozisyonla tasvir edilen figür yine bir asker azizdir. Sağ elinde mızrak, sol elinde kınında kılıç taşıyan bu azizin de kimliği sağ tarafında yer alması muhtemel yazıtı silindiği için anlaşılamamaktadır. 

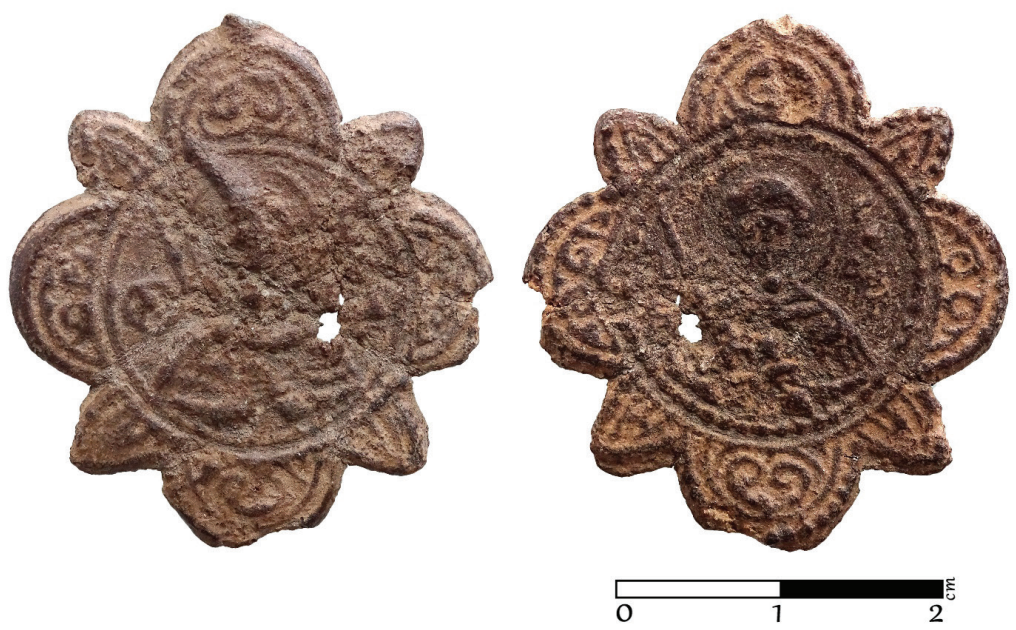

G. 15. Pandantif (enkolpion) (12.-14. yüzyıl) Ön ve arka yüz (Müze env no. HPM 15575) (Merve Toy, 2019)

8e. Envanter No. M15577

Ölçüler: $3 \times 2.8 \mathrm{~cm}$

Ön yüz: Bu yüzde nokta dizilerinden oluşan yuvarlak formlu madalyon içinde cepheden ve yarım boy asker aziz betimlenmiştir (G. 16). Yazıtı tahrip olduğu için kimliği anlaşılamayan azizin sağ elinde mızrak, sol elinde kınında kılıç yer alır. Solda Aziz monogramı görülmektedir.

Arka yüz: Diğerlerine benzer bir kurguya sahip bu yüzde de sağ elinde mızrak, sol elinde kınında kılıç taşıyan asker aziz bulunur. Figürün sol omuz başında Aziz monogramı eklenmiştir. Sağ omuz başında yer alan sütun sıralı $\Theta \epsilon O \Delta(O)$ harflerinden oluşan Yunanca yazıt, azizin kimliğini açıkça ortaya koyar. Burada tasvir edilen kişi Aziz Theodoros'tur. 

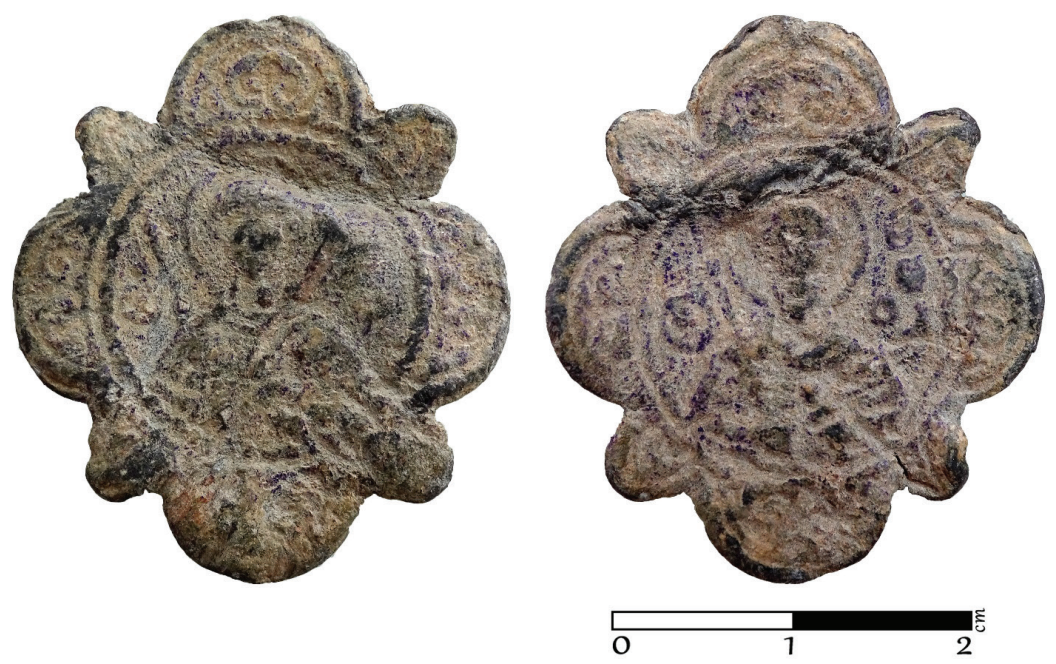

G. 16. Pandantif (enkolpion) (12.-14. yüzyıl) Ön ve arka yüz (Müze env no. HPM 15577) (Merve Toy, 2019)

8f. Envanter No. M15580

Ölçüler: $3.2 \times 2.8 \mathrm{~cm}$

Ön yüz: Oldukça tahrip olmakla birlikte bu yüzde yer alan figürün, sağ elinde mızrak, sol elinde kınında kılıç taşıyan bir asker aziz olduğu açıktır (G. 17). Solda kısmen silinmiş Aziz monogramına, sağda da silinmiş hâlde yazıta yer verilmiştir.

Arka yüz: Figürün sağ omuz başına istiflenmiş sütun sıralı $(\Theta) \in \mathrm{CO} \Delta(\mathrm{O})$ harflerinden oluşan Yunanca yazıttan anladığımız kadarıyla Aziz Theodoros'un betimlendiği bu objede aziz, sağ elinde mızrak, sol elinde kınında kılıç taşımaktadır. Figürün sol omzu başında da Aziz monogramı bulunur. 

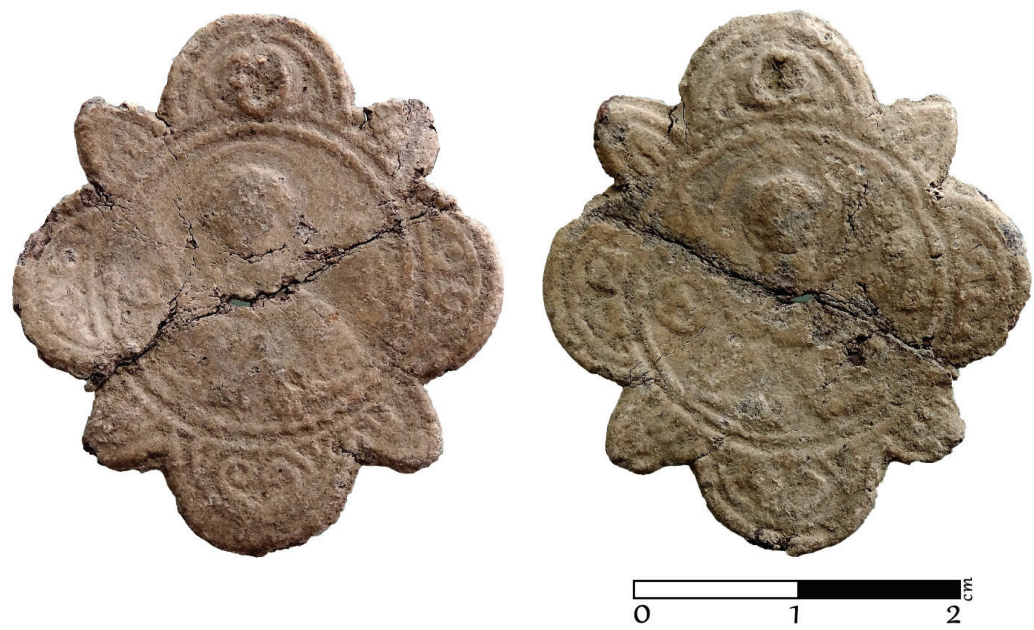

G. 17. Pandantif (enkolpion) (12.-14. yüzy1l) Ön ve arka yüz (Müze env no. HPM 15580) (Merve Toy, 2019)

Altı adet bronz pandantif (enkolpion) dört yapraklı yonca formu ile haç motifini vurgulamaktadır. 10. yüzyıldan itibaren benzer formda pandantifler (enkolpion) kullanılmaktadır ${ }^{85}$. Haluk Perk Müzesi koleksiyonunda yer alan dört yapraklı yonca formu içerisindeki haç şeklindeki pandantiflerin (enkolpion) 12.-14. yüzyıllar arasına tarihlendiği düşünülmektedir ${ }^{86}$.

\section{Sonuç}

Hristiyan öğretisinin yaygınlaşması sürecinde kişilere inancın koruyucu ve kötülüklerden arındırıcı yönünü gösterecek, onları Tanrı'ya ve Hristiyanlık inancına güçlü ve kopmaz bağlarla bağlayacak farklı inanç ve ibadet şekilleri ortaya çıkmıştır. Kendini Tanrı'ya ve inancına adayarak çilekeş ve münzevi bir yaşamı tercih eden kişiler, inançları uğruna ölümü bile göze alan martirler, Tanrı'nın ilahi gücü ve hikmetiyle türlü işkence ve eziyetlerden sarsılmaz inançlarıly kurtulan ilk inananlar, ilerleyen zamanlarda aziz ve azize mertebesine ulaştırılarak, inananlar tarafindan büyük hürmet görmüştür. Hristiyanlara hem iyi bir gerçek inanan modeli sunan, hem de arabulucu statüsüyle yardımcı olan bu kişiler, takanı koruduğu, hatta şifa dağıttığına inanılan türlü inanç objelerinde de sıklıkla betimlenmiştir. Keza bu kutsal kişilerin yaşadığı, gömüldüğü ya da şehit edildiği yerlerin inananlarca ziyaret edilmesi de Hristiyanlıkta hacı ve hacılık kavramının ortaya

85 Susan A. Boyd, "Quatrefoil Enkolpion," ed. H. Evans ve William D. Wixcom, The Glory of Byzantium. Art and Culture of Middle Byzantine Era, A.D. 843-1261 (New York: Metropolitan Museum of Art, 1997), 162, kat. no. 109; Ioli Kalavrezou, "Reliquary Enkolpion," Byzantium 330-1453, ed. R. Cormack ve M. Vassilaki (London: Royal Academy Publications, 2008), 229, 430, no.201; Ceren Ünal, "Balıkesir, Kuva-yi Milliye Müzesi'nden II. Nikephoros Phokas (963-969) Dönemine Ait Nadir Gümüş Sikke Miliaresion”, Ege Üniversitesi Sanat Tarihi Dergisi, XXIV/1 (Nisan 2016), 114-115.

86 Benzer örnek için bkz. Schmidt “Gold- Silber- und Bronzeikonen,” 181, 235. 
çıkmasına zemin hazırlamış, bu ziyarete ilişkin çeşitli objelerde bir tür anı ve koruyucu tılsım olarak inananların bedenlerinde uzak mesafelere taşınmıştır.

Haluk Perk Müzesi'nde bulunan ve bu makalede konu ettiğimiz on beş farklı eser de Bizans Dönemi'nde sanata yön veren inanç ve ibadet ilişkisini bir kez daha vurgularken, kutsal kişi ve kavramların sanat objeleri üzerine hangi gerekçeler ve ihtiyaçlar doğrultusunda yer aldığı hakkında bilgi vermektedir. Yapıldıkları malzemeler, kullanım şekilleri ve formları farklı olmasına rağmen, bu objelerin ortaya çıkmasındaki temel amaç, güçlü bir maneviyat eşliğinde, Tanrısal bir korumaya kavuşma, kendisi, ailesi ve sevdikleri için sağlıklı ve mutlu bir yaşam arzulama ve en nihayetinde günahların affını sağlayarak sonsuz ve mutlu yaşama adım atma düşüncesidir. Tanrısal koruma ve iyilik talebi kimi zaman iki küçük ikona (G. 3-G. 5) ve pandantiflerde (enkolpion) (G. 6-G. 8, G.12-G. 17) olduğu gibi kutsal kişiler aracılığıyla; kimi zaman ise kemer, bilezik ya da kolye parçası olduğu düşünülen üç adet bronz objeden ikisinde (G. 9, G. 11) görüldüğü gibi koruma ve yardım dileyen bir yazıtla dile getirilir. Hatta hacı nişanı/tokeni (G.1, G.2) örneğinde olduğu gibi bazen objenin malzemesi bile bu dinsel koruma ve şifanın bir parçası olabilmektedir. Haluk Perk Müzesi’nin Bizans koleksiyonu içindeki en ilgi çeken objelerinden biri olan hacı tokeni, Hristiyanların hacılık faaliyetini nasıl algıladığı hakkında da fikir vermektedir. Haluk Perk Müzesi koleksiyonundaki token ve benzeri hac objeleri, inananların hacılığa yalnızca kalplerini ve zihinleri maneviyatla dolduran kutsal bir ziyaret olarak bakmadığını; bu ziyaretin asıl nedeninin kutsal kişiyle aynı fiziki ortamı paylaşmak kadar, onun yardım ve mucizelerinden de bir ömür boyu yararlanmak isteği olduğunu açıkça ortaya koymaktadır. İkonografileri, üslupları ve benzer örnekleri göz önüne alınarak incelenip tarihlendirilmiş tüm bu eserler, içerdikleri bu kutsal anlamlar yanında, Bizans sanatının Anadolu buluntusu nadir ve özgün örnekleri olmaları bakımından da son derece önemlidir.

Hakem Değerlendirmesi: Dış bağımsız.

Çıkar Çatışması: Yazarlar çıkar çatışması bildirmemiştir.

Finansal Destek: Yazarlar bu çalışma için finansal destek almadığını beyan etmiştir.

Teşekkür: Değerli Koleksiyoner Sayın Haluk Perk’e Bizans sanatı ve kültürü açısından son derece önemli ve özgün örnekler barındıran koleksiyonunu bize açtığı, bu makalede konu edilen ve bilim dünyasıyla paylaşmamızın gerekli olduğunu düşündüğümüz önemli eserleri yayınlamamıza izin verdiği ve çalışmalarımız boyunca da desteğini esirgemediği için, çalışmamızın fotoğraf ve belgeleme aşamalarına titizlikle yardım eden sevgili öğrencimiz Uzman Sanat Tarihçi Merve Toy’a da emek ve katkıları için çok teşekkür ederiz. Bazı eserler üzerindeki Yunanca yazıtların transkripsiyonundaki değerli yardımları için de Uzman Sanat Tarihçi D. Markella Bakouri’ye ayrıca çok teşekkür ederiz.

Peer-review: Externally peer-reviewed.

Conflict of Interest: The authors have no conflict of interest to declare.

Grant Support: The authors declared that this study has received no financial support.

Acknowledgement: We would like to thank Dear Collector Mr. Haluk Perk, he opened his collection, which contains very important and unique examples in terms of Byzantine art and culture, our dear student, Expert Art Historian Merve Toy, for her work and contributions, as it allows us to publish important works that we consider necessary to share with the world of science and which we discuss in this article, and does not support her throughout our studies. We would also like to thank Expert Art Historian D. Markella Bakouri for his valuable help in transcription of Greek inscriptions on some works. 


\section{Kaynakça/References}

Bakirtzis, Charalambos. "Small Steatite Icon of St. Nicholas.” Ed. D. Papanikola-Bakirtzi. Everyday Life in Byzantium. Athens: Hellenic Ministry of Culture, 2002, 159.

Bank, Alice. Byzantine Art in the Collection of Soviet Museums. New York: Harry N. Abrams, 1978.

Bollmann, Beate. "Katalog-Die Entwicklung Der Christlich-Byzantinischen Kultur Syriens." Die Kunst Der Frühen Christen In Syrien, Zeichen, Bilder und Symbole. Vom. 4, Bis 7. Ed. M. Fansa ve B. Bolmann. Oldenburg: Mainz am Rhein, 2008, 144-189.

Boyd, Susan A. "Quatrefoil Enkolpion.” Ed. H. Evans ve William D. Wixcom. The Glory of Byzantium. Art and Culture of Middle Byzantine Era, A.D. 843-1261. New York: Metropolitan Museum of Art, 1997, 162.

Brown, Peter. "Yeni Toplum: Manastır Sistemi ve Hıristiyanlığın Yayılışı 300-400.” Geç Antik Çağda Roma ve Bizans Dünyası. İstanbul: Tarih Vakfi Yayınları, 2000, 57-67.

Carr, Annemarie Weyl. "Icons and the Object of Pilgrimage in Middle Byzantine Constantinople." Dumbarton Oaks Papers 56 (2002):75-92.

Cutler, Antony. "Ivory, Steatite, Enamel, and Glass." The Oxford Handbook of Byzantine Studies. Ed. E. Jeffries, R. Cormack ve J. Haldon. Oxford: Oxford University Press, 2008, 453-461.

Doran, Robert. The Lives of Simeon Stylites. Kalamazoo-Michigan: Cistercian Publications, 1992.

Eastmond, Antony. "Body vs. Column: The Cults of St. Symeon Stylites." Desire And Denial in Byzantium, Papers from the Thirty-first Spring Symposium of Byzantine Studies, University of Sussex, Brighton, March 1997. Ed. Liz James. Aldershot, UK: Ashgate Publishing, 1999, 87-100.

Elsner, Jas. “Art and Pilgrimage.” The Oxford Handbook of Byzantine Studies. Ed. E. Jeffreys, J. Haldon ve R. Cormack. Oxford: Oxford University Press, 2008, 741-750.

Entwistle, Chris. "Pilgrim Token with a Stylite." Byzantium: Treasures of Byzantine Art and Culture. Ed. D. Buckton. London: British Museum Press, 1994, 114.

Entwistle, Chris. "Pilgeramulett.” Byzanz Pracht und Alltag. Bonn: Hirmer Verlag, 2010, 221.

Evans, Helen ve William D. Wixcom. The Glory Of Byzantium, Art and Culture of the Middle Byzantine Era A.D. 843-1261. New York: The Metropolitan Museum of Art, 1997.

Foss Clive. "Pilgrimage in Medieval Asia Minor.” Dumbarton Oaks Papers 56 (2002): 129-151.

Fowden, Elizabeth Key. "Der Heiligenkult im Spätantiken Syrien.” Ed. M. Fansa ve B. Bollmann, Die Kunst Der Frühen Christen In Syrien, Zeichen, Bilder und Symbole, Vom. 4, Bis 7, Oldenburg: Mainz am Rhein, 2008, 56-62.

Grierson, Philip. Byzantine Coins. California: University of California Press, 1982.

Harvey, S. Ashbrook. "The Sense of a Stylite: Perspectives on Simeon the Elder." Vigiliae Christianae 42/4 (1988): 376-394.

Hennessy, Cecily. "Topography of Constantinople." The Oxford Handbook of Byzantine Studies. Ed. E. Jeffreys, J. Haldon ve R. Cormack. Oxford: Oxford University Press, 2008, 202-219.

Kalavrezou, Ioli. "Reliquary Enkolpion.” Byzantium 330-1453. Ed. R. Cormack ve M. Vassilaki, London: Royal Academy Publications, 2008, 430.

Kazdhan, Alexander ve Nancy Peterson Ševčenko. "George.” Oxford Dictionary of Byzantium, 1. cilt. New York: Oxford University Press, 1991, 834-835.

Kazdhan, Alexander ve Nancy Peterson Ševčenko. "Nicholas of Myra.” Oxford Dictionary of Byzantium, 2. cilt. New York: Oxford University Press, 1991, 1469-1470. 
Kazdhan, Alexander ve Nancy Peterson Ševčenko. "Onouphrios.” Oxford Dictionary of Byzantium, 2. cilt. New York: Oxford University Press, 1991, 1527.

Kazdhan, Alexander ve Nancy Peterson Ševčenko. "Theodore Stratelates.” Oxford Dictionary of Byzantium, 3. cilt. New York: Oxford University Press, 1991, 2047.

Kiraz, Mine. "Koruyucu Gögüs Pandantifi (enkolpion).” Hayat Kısa, Sanat Uzun Bizans 'ta Şifa Sanatı. İstanbul: Pera Müzesi Yayınları, 2015, 363.

Lent, Frederick. "The Life Of St. Simeon Stylites: A Translation of the Syriac Text in Bedjan's Acta Martyrum et Sanctorum, Vol. IV." Journal of the American Oriental Society 35 (1915): 103-198.

Lianta, Eleni. Late Byzantine Coins 1204-1453. London: Spink Books, 2009.

Maraval, Pierre. "The Earliest Phase of Christian Pilgrimage in the Near East (Before the 7th century)." Dumbarton Oaks Papers 56 (2002): 63-74.

Majeska, George P. “A Medallion of the Prophet Daniel in the Dumbarton Oaks Collection." Dumbarton Oaks Papers 28 (1974): 361-366.

Merantzas, Christos. "Bizans Kültüründe Benliğin Vücut Bulması.” Hayat Kısa, Sanat Uzun Bizans 'ta Şifa Sanatı. İstanbul: Pera Müzesi Yayınları, 2015, 181-191.

Mitchell, Stephen. Geç Roma Imparatorluğu M.S. 284-641. Çev. T. Kaçar. Ankara: Türk Tarih Kurumu Yayınları, 2016.

Nesbitt, John. "Sigillography.” The Oxford Handbook of Byzantine Studies. Ed. E. Jeffreys, J. Haldon ve R. Cormack. Oxford: Oxford University Press, 2008, 150-157.

Nesbitt, John. Catalogue of Byzantine Seals at Dumbarton Oaks and in the Fogg Museum of Art. 6. Cilt. Washington D.C.: Harvard University Press, 2009.

Osborne, John. "Politics, Diplomacy and the Cult of Relics in Venice and the Northern Adriatic in the First Half of the Ninth Century." Early Medieval Europe 8/3 (1999): 369-386.

Ostrogorsky, Georg. Bizans Devleti Tarihi. Çev. F. Işıltan. Ankara: Türk Tarih Kurumu Yayınları, 2015.

Paphnutius. Histories of the Monks of Upper Egypt and The Life of Onnophrius. Çev. Tim Vivian. NJ, USA: Gorgias Press, 2009.

Pentcheva, Bissera V. “The 'Activated' Icon: the Hodegetria Procession and Mary's Eisodos.” Images of the Mother of God. Ed. M. Vassilaki. Norfolk: Ashgate Publishing, 2005, 195-207.

Pentcheva, Bissera V. Icons and Power: The Mother of God in Byzantium. Pennsylvania: Pennsylvania State University Press, 2006.

Phoskolou V. “Jasper Cameo with Daniel in The Lion's Den.” Everyday Life in Byzantium. Ed. D. Papanikola-Bakirtzi. Athens: Hellenic Ministry of Culture, 2002, 519.

Piatnitsky, Yuri. "The Divine Light of The Faith and Power." Pilgrim Treasures from the Hermitage, Byzantium-Jerusalem. Amsterdam: Lund Humphries, 2005, 18-71.

Pitarakis, Brigitte. "Female Piety in Context." Images of the Mother of God. Ed. M. Vassilaki, Norfolk: Ashgate Publishing, 2005, 153-166.

Pitarakis, Brigitte. "Şifayı Güçlendirmek Maddeler, Duyular ve Ritüeller." Hayat Kısa, Sanat Uzun Bizans 'ta Şifa Sanatı. İstanbul: Pera Müzesi Yayınları, 2015, 163-179.

Restle, Marcel. Die Byzantinische Wandmalerei in Kleinasien, 3 Cilt, Germany: Verlag Aurel Bongers, 1967.

Ross, Leslie. “Onuphrius, Saint.” Medieval Art: A Topical Dictionary. Westport CT: Greenwood Press, 1996, 189. 
Ross, Leslie. "Onuphrios." Holy People of the World, Cross-Cultural Encyclopedia. 2. cilt. Ed. Phyllis G. Jestice. USA: ABC-CLIO, 2004, 657.

Schmidt, Christian. "Gold- Silber- und Bronzeikonen-Bild und Bilderkult." Die Welt von ByzanzEuropas Östliches Erbe. München: Theiss, 2004, 149-183.

Ševčenko, Nancy Peterson. "Virgin Blachernitissa." Oxford Dictionary of Byzantium. 3. cilt. New York: Oxford University Press 1991, 2170-2171.

Ševčenko, Nancy Peterson. "Virgin Hodegetria." Oxford Dictionary of Byzantium, 3. cilt. New York: Oxford University Press 1991, 2172-2173.

Talbot, Alice-Mary. “Bizans Manastır Sistemine Giriş.” COGITO 17 (1999), 160-175.

Talbot, Alice-Mary. "Hagiography." The Oxford Handbook of Byzantine Studies. Ed. E. Jeffreys, J. Haldon ve R. Cormack. Oxford: Oxford University Press, 2008, 862-872.

Tsakalos, Antonis. "Lead Pilgrim Token of St. Symeon." Everday Life in Byzantium. Ed. D. Papanikola-Bakirtzi. Athens: Hellenic Ministry of Culture, 2002, 177.

Tural, Murat. Sütun Tepesinde Bir Ömür Aziz Simeon. İstanbul: Arkeoloji Sanat Yayınları, 2018.

Ünal, Ceren. "Balıkesir, Kuva-yi Milliye Müzesi’nden II. Nikephoros Phokas (963-969) Dönemine Ait Nadir Gümüş Sikke Miliaresion”. Ege Üniversitesi Sanat Tarihi Dergisi XXIV/1 (Nisan, 2016): 107-120.

Varalis, Yannis D. "Steatite Icon of St. Nicholas." Everyday Life in Byzantium. Ed. D. PapanikolaBakirtzi. Athens: Hellenic Ministry of Culture 2002, 159-161.

Vassilaki, Maria. "Icons." The Oxford Handbook of Byzantine Studies. Ed. E. Jeffreys, J. Haldon ve R. Cormack. Oxford: Oxford University Press, 2008, 758-770.

Verdier, Philippe. "A Medallion of Saint Symeon the Younger." The Bulletin of the Cleveland Museum of Art 67/1 (1980): 17-26.

Vikan, Gary. "Pilgrimage." Oxford Dictionary of Byzantium, 3. cilt. New York: Oxford University Press, 1991, 1676-1677.

Vikan, Gary. "Steatite.” Oxford Dictionary of Byzantium. 3. cilt. New York: Oxford University Press, 1991, 1947.

Vikan, Gary. "Pilgrim Tokens," Oxford Dictionary of Byzantium. 3. cilt. New York: Oxford University Press, 1991, 1678.

Vikan, Gary. Byzantine Pilgrimage Art. Washington D. C.: Harvard University Press, 1982.

Witt, Janette. "Styliten-Medallions." Rom und Byzanz Archäologische Kostbarkeiten aus Bayern. München: Hirmer Verlag, 1998, 106-107.

Witt, Janette. "Sech Erdmedallions mit Stylitendarstellungen." Byzanz Das Licht aus dem Osten. Mainz: Verlag Phillip von Zabern, 2001, 183-184.

Witt, Janette. "Die Syrischen Säulenheiligen-Reliquien und Wallfahrt." Die Welt von ByzanzEuropas Östliches Erbe. München: Theiss, 2004, 185-211.

Witt, Janette. "Sechs Erdmedallions-Reliquien und Wallfahrt." Die Welt von Byzanz-Europas Östliches Erbe. München: Theiss, 2004, 185-211.

Woods, David. "Some Dubious Stylites on Early Byzantine Glassware." Journal of Glass Studies 46 (2004): 39-49.

Yandım, Sercan. "Sinop Arkeoloji Müzesi'nde Bulunan İkonalar." 26. Araştırma Sonuçları Toplantısı. 2. cilt. Ankara: T.C. Kültür ve Turizm Bakanlığı Yayınları, 2009, 267-282. 
Zalesskaya, Vera. "Souvenirs of the Holy Land." Pilgrim Treasures from the Hermitage, ByzantiumJerusalem. Amsterdam: Lund Humphries, 2005, 72-88.

Zenbilci, İlkgül Kaya. "Münzevi Yaşam Fikrinin Bizans Tasvirlerindeki Yansımaları: Sütun Üzerinde Yaşayan Azizler.” Sosyal Bilimlerde Güncel Akademik Çalışmalar-2018, III. cilt. Ed. M. Evsile, İ. Serbestoğlu ve T. Öcan. Ankara: Gece Kitaplığı, 2018, 1-37. 
